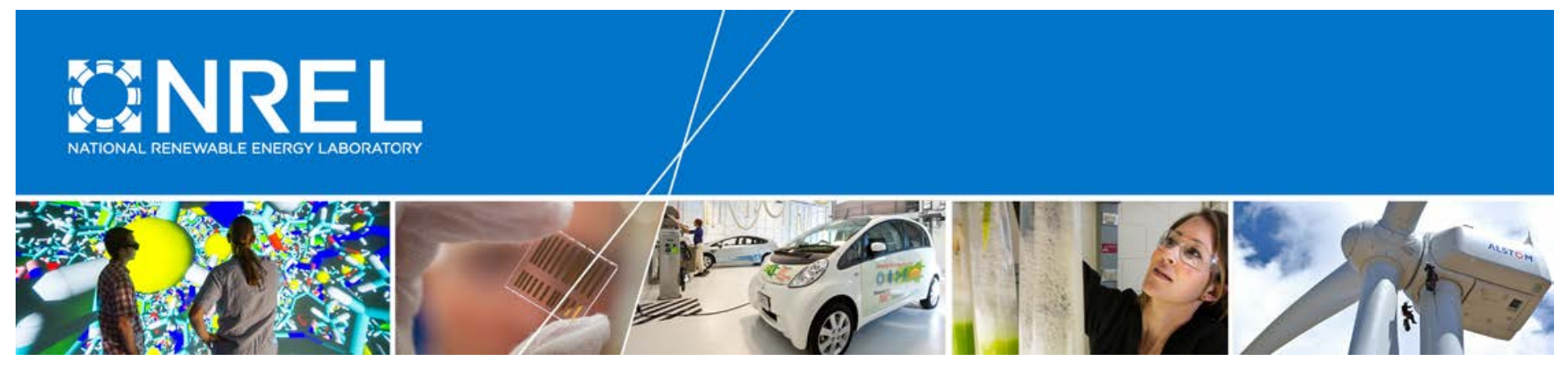

\title{
Expanding PV Value: Lessons \\ Learned from Utility-led \\ Distributed Energy Resource \\ Aggregation in the \\ United States
}

Jeffrey J. Cook, Kristen Ardani, Eric O'Shaughnessy, Brittany Smith, and Robert Margolis

National Renewable Energy Laboratory

NREL is a national laboratory of the U.S. Department of Energy Office of Energy Efficiency \& Renewable Energy

Operated by the Alliance for Sustainable Energy, LLC

This report is available at no cost from the National Renewable Energy Laboratory (NREL) at www.nrel.gov/publications.

Technical Report

NREL/TP-6A20-71984

November 2018

Contract No. DE-AC36-08GO28308 


\section{Expanding PV Value: Lessons Learned from Utility-led Distributed Energy Resource Aggregation in the United States}

Jeffrey J. Cook, Kristen Ardani, Eric O'Shaughnessy, Brittany Smith, and Robert Margolis

National Renewable Energy Laboratory

\section{Suggested Citation}

Cook, Jeffrey J., Kristen Ardani, Eric O'Shaughnessy, Brittany Smith, and Robert Margolis. 2018. Expanding PV Value: Lessons Learned from Utility-led Distributed Energy Resource Aggregation in the United States. Golden, CO: National Renewable Energy Laboratory. NREL/TP-6A20-71984. https://www.nrel.gov/docs/fy19osti/71984.pdf.
National Renewable Energy Laboratory 15013 Denver West Parkway Golden, CO 80401

303-275-3000 • www.nrel.gov
NREL is a national laboratory of the U.S. Department of Energy Office of Energy Efficiency \& Renewable Energy Operated by the Alliance for Sustainable Energy, LLC

This report is available at no cost from the National Renewable Energy Laboratory (NREL) at www.nrel.gov/publications.

\section{Technical Report}

NREL/TP-6A20-71984

November 2018

Contract No. DE-AC36-08GO28308 


\section{NOTICE}

This work was authored by the National Renewable Energy Laboratory, operated by Alliance for Sustainable Energy, LLC, for the U.S. Department of Energy (DOE) under Contract No. DE-AC36-08G028308. Funding provided by U.S. Department of Energy Office of Energy Efficiency and Renewable Energy Solar Energy Technologies Office. The views expressed in the article do not necessarily represent the views of the DOE or the U.S. Government.

This report is available at no cost from the National Renewable Energy Laboratory (NREL) at www.nrel.gov/publications.

U.S. Department of Energy (DOE) reports produced after 1991 and a growing number of pre-1991 documents are available free via www.OSTI.gov.

Cover Photos by Dennis Schroeder: (left to right) NREL 26173, NREL 18302, NREL 19758, NREL 29642, NREL 19795.

NREL prints on paper that contains recycled content. 


\section{Acknowledgments}

This work was funded by the U.S. Department of Energy's Solar Energy Technologies Office. The authors would like to thank all the interviewees for contributing their expertise to this study. We also would like to thank the following individuals and organizations for their review of this work: Dan Bilello (National Renewable Energy Laboratory), Lori Bird (National Renewable Energy Laboratory), Jaquelin Cochran (National Renewable Energy Laboratory), Anna Ebers (Department of Energy), Craig Ferreira (Green Mountain Power), Sergio Islas (Southern California Edison), Lupe Jimenez (Sacramento Municipal Utility District), Greggory Kresge (Maui Electric Company), Olaf Lohr (Sonnenbatterie), Sunao Masunaga (Hitachi), Alex Portilla (Pacific Gas \& Electric), Paul Schwabe (National Renewable Energy Laboratory), Kurt Stogdill (Austin Energy), and Mark Williams (Sunverge). Finally, we would like to thank Jarett Zuboy for editorial support. 


\section{List of Acronyms}

$\begin{array}{ll}\text { AHJ } & \begin{array}{l}\text { authority having jurisdiction } \\ \text { combined heat and power }\end{array} \\ \text { CHP } & \begin{array}{l}\text { Consolidated Edison } \\ \text { distributed energy resource } \\ \text { distributed energy resource management system(s) } \\ \text { DER }\end{array} \\ \text { distributed generation } \\ \text { DG } & \text { electric vehicle } \\ \text { EV } & \text { Green Charge Network } \\ \text { GCN } & \text { General Electric } \\ \text { GE } & \text { Hawaiian Electric Company } \\ \text { HECO } & \text { Maui Electric Company } \\ \text { MECO } & \text { New York State Energy Research and Development } \\ \text { NYSERDA } & \text { Authority } \\ & \text { Pacific Gas \& Electric } \\ \text { PG\&E } & \text { Preferred Resources Pilot } \\ \text { PRP } & \text { photovoltaic(s) } \\ \text { PV } & \text { Southern California Edison } \\ \text { SCE } & \text { Sacramento Municipal Utility District } \\ \text { SMUD } & \text { state of charge }\end{array}$




\section{Executive Summary}

Distributed residential photovoltaic (PV) capacity in the United States increased from about 0.4 GW in 2010 to 10.5 GW in 2017 (GTM Research and SEIA 2018). Distributed PV and other emerging distributed energy resources (DERs) like battery storage and electric vehicles (EVs) may provide demand response, voltage regulation, and other grid services. When many DERs are aggregated and called upon to provide certain services simultaneously, they may provide the distribution grid with ancillary and other services that enhance reliability. These initiatives are often referred to as DER aggregation or virtual power plants. If nascent U.S. utility-led DER aggregation projects prove successful, new value streams could open for PV and other emerging DERs, thereby expanding deployment and transforming the energy market.

The literature on the scope, performance, and lessons learned from utility-led DER aggregation projects is limited. This report fills the research gap by surveying such programs nationwide and then analyzing five project case studies to compare lessons learned and identify common challenges and solutions that other utilities might consider when developing next-generation pilots and programs.

We identified 23 utility-led DER aggregation initiatives nationwide (Figure ES-1). The earliest project was launched by Bonneville Power Administration in 2009, while most were launched after 2014. There is significant geographic diversity in the programs; Arizona, California, and Hawaii are the only states with more than one utility-led DER aggregation program.

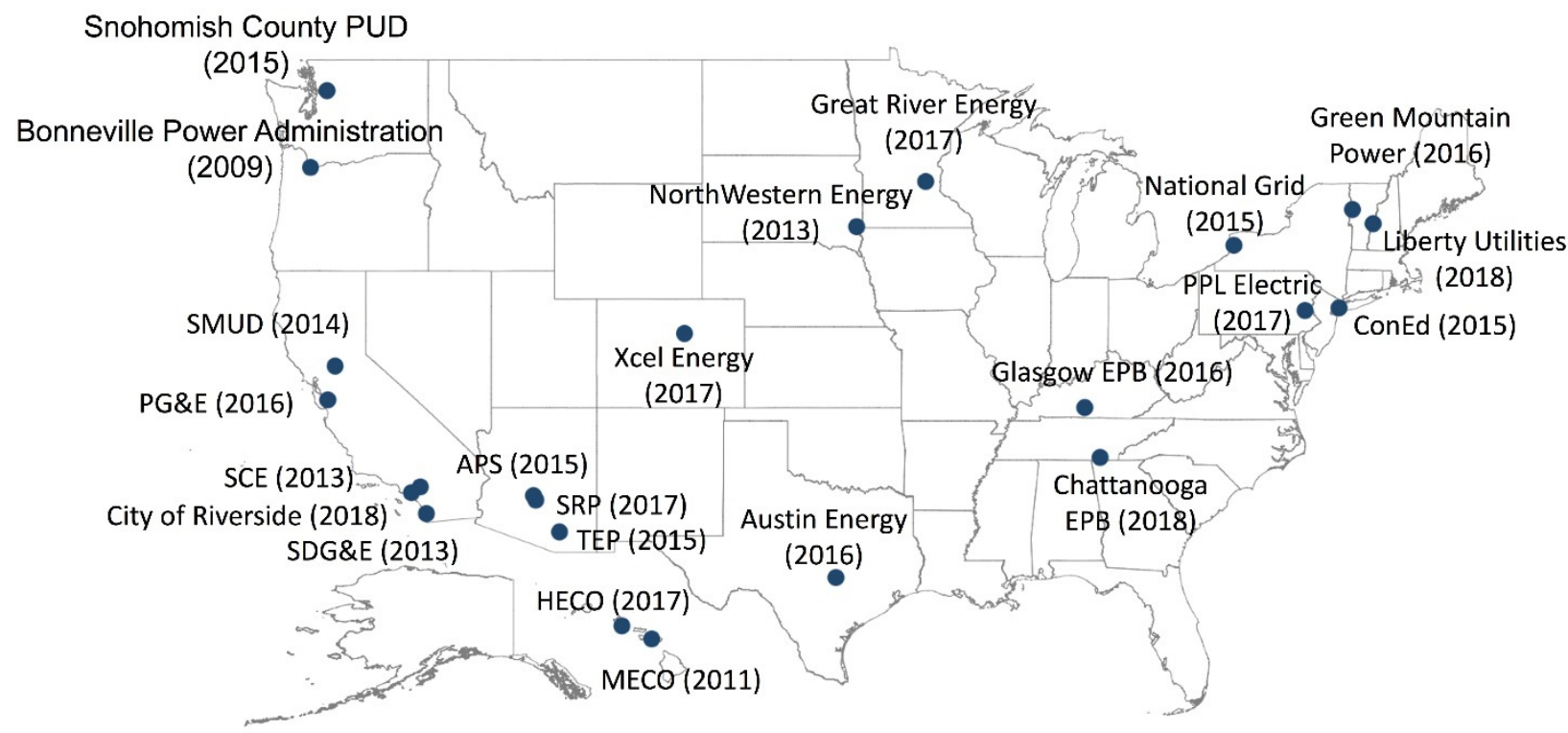

Figure ES-1. DER aggregation efforts by utility (year launched in parentheses)

We selected the following five projects as case studies, because they incorporated PV, published data on DER performance, and had diverse characteristics such as project capacity and types of DERs involved:

- Green Mountain Power - McKnight Lane Redevelopment Project 
- Maui Electric Company (MECO) - JumpSmart Maui Project

- Pacific Gas \& Electric (PG\&E) - San Jose EPIC Distributed Energy Resource Demonstration Projects

- Southern California Edison (SCE) - Preferred Resources Pilot

- Sacramento Municipal Utility District (SMUD) - 2500 R Midtown Project

To analyze and compare the cases, we collected archival data and completed interviews with 27 subject-matter experts, including engineers, program managers, software developers, and other key partners. Overall, the unique design, scope, and timeline of each project complicates comparison of DER performance and related grid value across the projects. For example, project sizes vary from $0.04 \mathrm{MW}$ of PV in the Green Mountain Power project to $51 \mathrm{MW}$ in SCE's. Even so, each project demonstrated that DER aggregation can provide grid benefits including frequency response, load shifting, and voltage regulation among others. As one example, SMUD found that controlling DERs at 10 homes provided an average load reduction of $2.66 \mathrm{~kW}$ per house and an aggregate $44 \mathrm{~kW}$ of load-shifting capability at peak.

Despite project design differences, there were commonalities in the lessons learned across each project that may be of interest to other utilities considering new aggregation programs. Across the cases, we identified five categories of challenges relating to distributed energy resource management system (DERMS) development and implementation, customer acquisition, DER deployment, communication with DERs, and DER performance. In some cases, the utilities faced similar issues within a given category. For example, three of the five utilities had challenges with developing DERMS software to control a disparate set of DER technologies and participants. In other cases, the utilities' experiences and challenges varied substantially. For example, Green Mountain Power, PG\&E, and SCE found that DERs performed as expected, whereas the other two utilities found that the performance of different technologies varied.

Based on this common set of challenges and the perspectives from interviewees, we offer considerations for next-generation DER aggregation programs, including the following:

- To scale DER aggregation programs, utilities likely need to develop a DERMS and find cost-effective pathways to integrate DERs with different communication protocols.

- To secure customer participation, utilities should consider how DER aggregation will impact or align with existing DER incentive structures so that potential customers see a net benefit of participation.

- To reduce deployment-related delays, utilities could work proactively with AHJs to resolve permitting issues particularly for batteries.

- To secure anticipated grid services from deployed DERs, utilities likely need to pursue methods to increase communication reliability between the utility, aggregators, and/or individual DERs.

- To more accurately predict DER performance, utilities should evaluate how technology mix, operation protocols, and consumer behavior may impact individual DER performance. 


\section{Table of Contents}

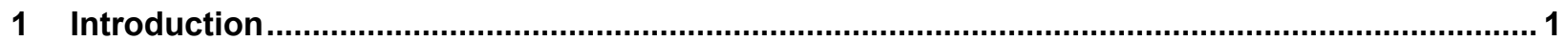

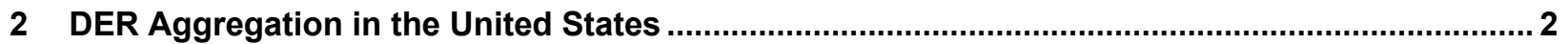

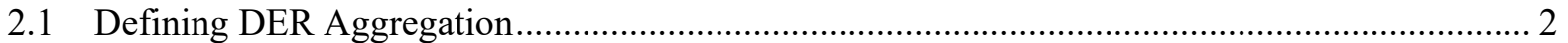

2.2 DER Aggregation Components and Structure .................................................................... 3

3 DER Aggregation Program Landscape in the United States ..................................................... 5

4 DER Aggregation Program Design and Performance ............................................................... 7

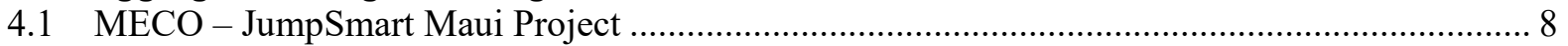

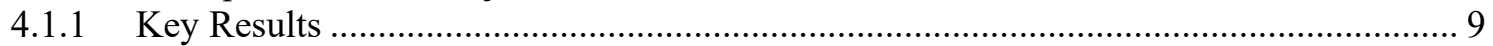

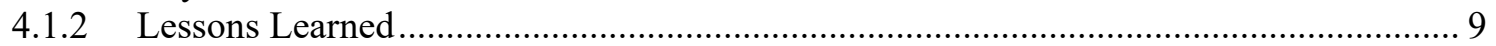

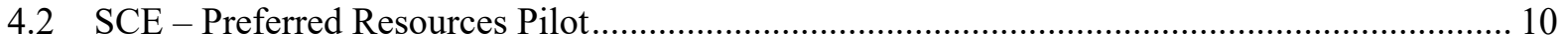

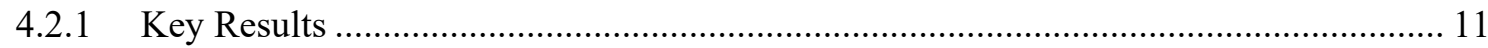

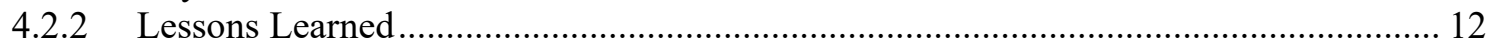

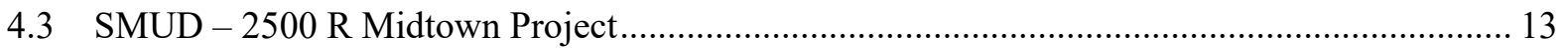

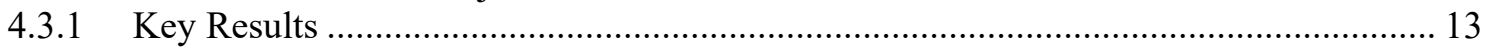

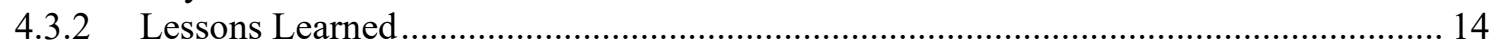

4.4 Green Mountain Power - McKnight Lane Redevelopment Project.......................................... 15

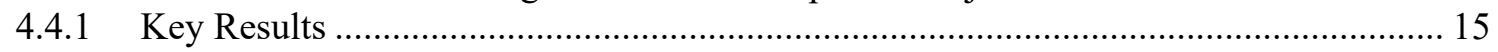

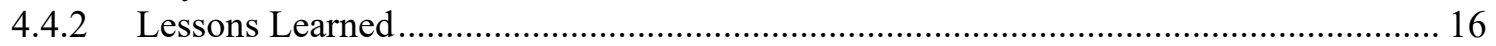

4.5 Pacific Gas \& Electric - San Jose EPIC Distributed Energy Resource Demonstration Projects 17

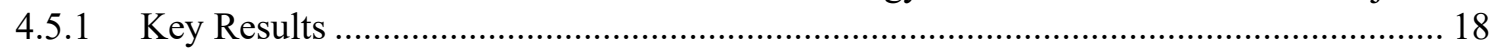

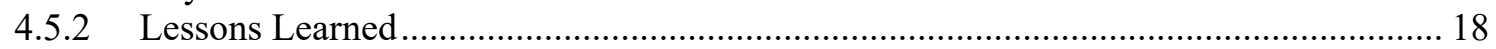

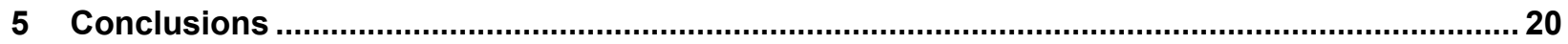

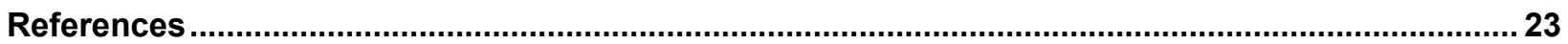

Appendix 


\section{List of Figures}

Figure ES-1. DER aggregation efforts by utility (year launched in parentheses) ......................................

Figure 1. Example DER aggregation program structure and component interaction ................................. 4

Figure 2. DER aggregation initiatives in the United States, by utility (year launched in parentheses) ........ 6

Figure 3. JumpSmart Maui Project EV load-shifting performance, September 2016 (recreated from Irie 2017)

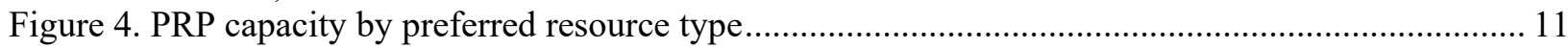

Figure 5. Assessed DER performance and customer demand for 2 days in PRP region; the demand shown is peak demand above baseline demand of $971 \mathrm{MW}$ (recreated from SCE 2018).

Figure 6. Total household fleet Ioad-shifting profile for an average conservation day (recreated from ADM Associates Inc. 2014)

Figure 7. Battery and PV operation from one duplex around the monthly ISO New England peak period, February 2018 (recreated from Donalds, Galbraith, and Olinsky-Paul 2018) ....................... 16

Figure 8. Example of DERMS-forecasted overload mitigation (recreated from Portilla 2017) ................ 18

\section{List of Tables}

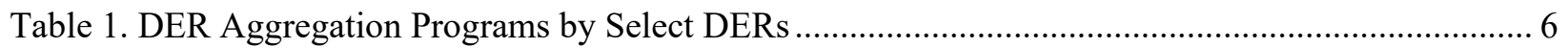

Table 2. Summary Comparison of Utility Projects ..................................................................... 7

Table 3. Summary of Key DER Program Challenges by Utility and Category ....................................... 20

Table 4. Identified Utility-led DER Aggregation Programs by Year 


\section{Introduction}

In 2010, less than $0.4 \mathrm{GW}$ of distributed residential solar photovoltaics (PV) were installed in the United States. In 2017, cumulative residential PV deployment grew to $10.5 \mathrm{GW}$, representing a nearly 30 -fold increase in installed capacity over that period (GTM Research and SEIA 2018). Though distributed PV generation accounts for about $0.5 \%$ of total electricity generation nationwide, high PV penetration can present localized electric grid challenges. These challenges stem from the grid's design as a one-way power flow from the utility to the end-user. The introduction of non-utility-owned distributed energy resources that export power back to the grid along with limited visibility into these assets' generation can cause unexpected backflow, voltage fluctuations, and steep demand ramps (EIA 2018; Coddington, Miller, and Katz 2016; Denholm, Clark, and O'Connell 2016).

Several mitigation options can address grid-integration challenges presented by increasing levels of PV penetration (Braff, Mueller, and Trancik 2016; Lazar 2016). This paper focuses on one strategy - aggregating multiple distributed energy resources (DERs) to create conditions that provide grid-support functions not enabled by individual DERs (Braff, Mueller, and Trancik 2016; Feblowitz 2017; Shallenberger 2017).

Though utilities have a long history of leveraging individual DERs for certain grid services, such as load control for demand response programs, utility efforts to use a broader suite of DER capabilities through aggregation are still emerging. If initial DER aggregation programs prove successful, they could enable utilities and end users to access new value streams for PV and other emerging DERs, thereby increasing DER functionality and transforming how energy is generated and delivered.

This study is one of the first efforts to document variation in aggregation programs, results, and lessons learned. To date, 23 utility-led DER aggregation projects have been implemented nationwide. We analyze five utility pilots to identify commonalities and differences in approach, scope, technology configuration, and other aspects of program design and implementation. Through personal interviews with 27 subject-matter experts and a comparative analysis, we identify key considerations, challenges, and related solutions for aggregation of PV and other DERs to inform development of next-generation programs.

The remainder of this report is structured as follows. Section 2 defines and describes DER aggregation. Section 3 surveys the utility-led DER aggregation landscape in the United States. Section 4 presents five case studies of DER aggregation projects. Section 5 summarizes the common challenges encountered across these projects and offers perspectives on possible solutions from interviewees involved in the efforts. The appendix contains a comprehensive list of all the DER aggregation initiatives implemented to date in the United States. 


\section{DER Aggregation in the United States}

There is no universal definition of what constitutes DER aggregation, and DER aggregation programs can take a variety of forms. This section defines the types of DER aggregation considered in this report.

\subsection{Defining DER Aggregation}

Utilities and regional grid operators have a long history of working with residential, commercial, and industrial customers to control or manage certain DERs, typically through load control for demand response programs. In these programs, customers can opt in and provide load reduction during certain peak demand periods. This load reduction allows the utility to avoid relying on higher cost peaking generation resources, such as natural gas combustion turbines. The utility then compensates the participants for their load reductions. In 2015, about $9 \mathrm{GW}$ of residential, 7 $\mathrm{GW}$ of commercial, and $17 \mathrm{GW}$ of industrial load participated in retail demand response programs (FERC 2017).

In aggregate, the participation of numerous residential and commercial customers in demand response programs can provide significant load reduction and grid benefits to the utility. However, the contribution to load reduction on a per-customer basis is low. At the same time, participation in these programs has historically required customer time and resources that may hinder participation. To address this challenge, third-party companies have emerged to serve as intermediaries between these customers and the utility to provide demand response services at lower cost to the customer (Tweed 2010). These "aggregators" enlist residential and commercial customers in utility-sponsored demand response programs and then respond to utility calls for load reduction on behalf of the customers.

The genesis of broader DER aggregation programs has emerged from the success of these demand response programs. Demand response programs have focused on traditional load-control opportunities including adjusting heating and cooling, lighting, and manufacturing production schedules, among others. The proliferation of distributed PV, battery storage, electric vehicles (EVs), and other DERs has opened new opportunities for load shifting. In addition, these technologies - when used in certain combinations - can provide a variety of other grid-related services, ${ }^{1}$ including the following:

- Voltage regulation, i.e., maintaining reliable and constant voltage within a transmission or distribution line to ensure electrical equipment is not damaged owing to over- or under-voltage.

- Contingency response, i.e., maintaining frequency in response to an unexpected failure or outage of a system component (e.g., generator, transmission line).

- Regulating reserves, i.e., maintaining frequency during normal (non-event) conditions.

The ability to provide these services and respond to utility requests for load control allows DER customers to deliver services similar to those offered by conventional power plants. As is the case with demand response programs, one DER customer provides fewer grid services than

\footnotetext{
${ }^{1}$ Providing these services may impact operation of DERs and might require different compensation structures that are not explored here.
} 
aggregating multiple DERs and dispatching them simultaneously. This type of DER aggregation - also known as a virtual power plant — is the focus of this report.

\subsection{DER Aggregation Components and Structure}

Aggregation is a new paradigm that can augment traditional utility service models, but may require utility investments in dispatch platforms as well as third-party investments in control, communication, and dispatch of the aggregated DERs. Here we describe the basic components of DER aggregation and how they may be structured to provide grid services.

DER aggregation requires three fundamental components: a communication software platform, communication-capable hardware, and DERs (Figure 1). The communication software platform serves as the framework for a grid operator to send market signals to third-party aggregators, DER customers, or DERs directly. These entities can then decide whether to respond to those market signals with the requested grid service. Though many utilities have developed demand response management systems to support their peak load reduction programs, using DERs for broader grid services often requires incorporating these resources into their dispatch and distribution management systems. Some utilities have filled this need by developing new distributed energy resource management systems (DERMS) designed, in part, to manage DERs to support multiple grid and asset objectives optimally (Mulherkar 2017; Seal, Renjit, and Deaver 2018). From this software platform, the utility can directly control individual DERs, send signals to DER customers, request services of third parties, or combine all three tasks. Thirdparty aggregators have also developed their own communication software platforms to manage, control, and respond to utility requests. These systems are designed to interface with utility systems and maximize the value of DERs to utilities and customers.

To participate in these programs, customer-sited DERs must be equipped with communication hardware that allows the DER assets to respond to a utility, third-party aggregator, or DER customer request. This communication is often transmitted through wireless internet or mobile phone networks. The utility or aggregator transmits a signal from its software to the DER's communication hardware, which deciphers that signal and responds. Whether the DER provides the grid service is often contingent upon the priorities of the DER customer or the design of the program. Should the DER respond to the call, the communication hardware also tracks the DER's output to the grid and submits those data back to the utility or third-party aggregator. These data serve as the basis for establishing appropriate compensation. PV and batteries equipped with some types of advanced inverters are compatible with these communication pathways, as are certain "smart" home devices such as smart thermostats and EV chargers.

The third key component of an aggregation program is a fleet of DERs. A DER is any device that can be remotely controlled to consume and/or export electricity at a specified time. DERs can include PV, battery storage, EVs, smart home appliances, diesel generators, and other technologies. The type of DERs eligible to participate in aggregation may depend on the program design and other regulatory factors. For example, there may be siting, environmental, and other requirements that must be met to participate.

Though all DER aggregation programs incorporate these three components, program design and control of DERs vary widely. In some cases, the utility may directly manage all the DERs on the utility grid. In others, a utility may send market signals to aggregators and DER customers, 
which then respond and dispatch DERs to meet the utility's needs. The intent here is not to document exhaustively the various programmatic structures that could be employed for DER aggregation. Instead, we offer one illustrative example that demonstrates the DER aggregation concept, as summarized in Figure 1.

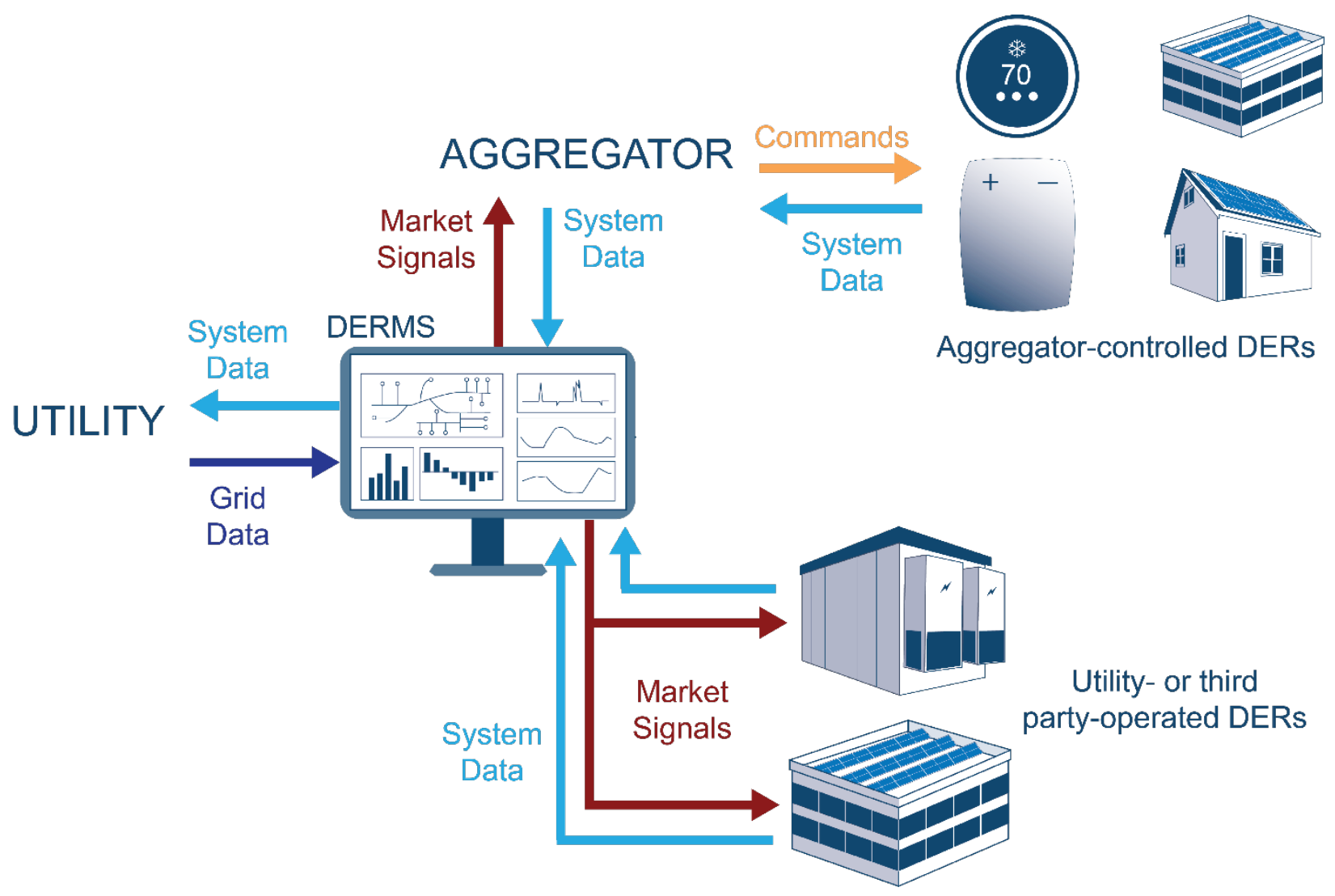

Figure 1. Example DER aggregation program structure and component interaction

In this example, the utility manages a DER aggregation program through a DERMS platform. The DERMS, which has access to grid conditions, sends market signals to an aggregator as well as individual DERs on the system. The aggregator then sends commands to participant DERs to respond to the call from the DERMS. The aggregator collects the individual DER performance data and submits those data back to the utility via the DERMS. In addition, the individual DERs participating in the program respond to the DERMS command based on the priorities of the individual DER customer. The system data are then transmitted back to the DERMS, and the utility compensates the aggregator and other relevant DER customers based on system performance. 


\section{DER Aggregation Program Landscape in the United States}

DER aggregation programs are relatively new, with the first successful pilot launched in Germany in 2008 (Patel 2012, Feblowitz 2017). Since then, utilities from Australia to the United States have been experimenting with DER aggregation (Reuters 2018, Colthorpe 2017). However, the broad spectrum of DER aggregation initiatives has not been centrally documented and tracked, making it challenging to assess the scope of DER aggregation, performance, and lessons learned. This section helps address the literature gap by summarizing utility-led DER aggregation in the United States. ${ }^{2}$

The definition and implementation of DER aggregation can vary widely across electric utilities. For the purposes of this report, any utility effort to control and manage multiple DERs to provide grid services is considered DER aggregation. Employing this definition, we developed a national data set of utility projects and programs through a review of DER market reports, utility publications, and other materials (for the full data set see Appendix). ${ }^{3}$

From this approach, we identified 23 utility-led DER aggregation initiatives across the United States (Figure 2). ${ }^{4}$ We interviewed utility representatives from 12 of the 23 DER aggregation programs to collect additional data on design, unique attributes, and lessons learned. Bonneville Power Administration and partner utilities launched the first project in 2009, and Maui Electric Company (MECO) launched the second in 2011. Following these early adopters, most subsequent DER projects were launched after 2014. Though there is significant geographic diversity in the data set, five of the projects are in California, while Arizona and Hawaii are the only other states with more than one project. ${ }^{5}$

\footnotetext{
2 Though this report focuses on utility-led aggregation, certain regional grid operators either operate or are considering DER aggregation programs, including the California Independent System Operator, PJM Interconnection, and the New York Independent System Operator (Gundlach and Webb 2018).

${ }^{3}$ This archival research was supported by data derived from interviewees.

${ }^{4}$ Some utilities may have more than one initiative to aggregate certain DERs, such as Green Mountain Power (Colthorpe 2017). Given the DERs are often integrated into one DERMS, we consider these different DER programs under one DER aggregation umbrella for this report.

${ }^{5}$ Utility service territories can cross state lines, which may impact how many states may be included in at least one utility-led DER aggregation program. In addition, Hawaiian Electric Industries is the parent company of both Hawaiian Electric Company (HECO) and MECO, so these two programs could be considered as led by the same parent utility.
} 


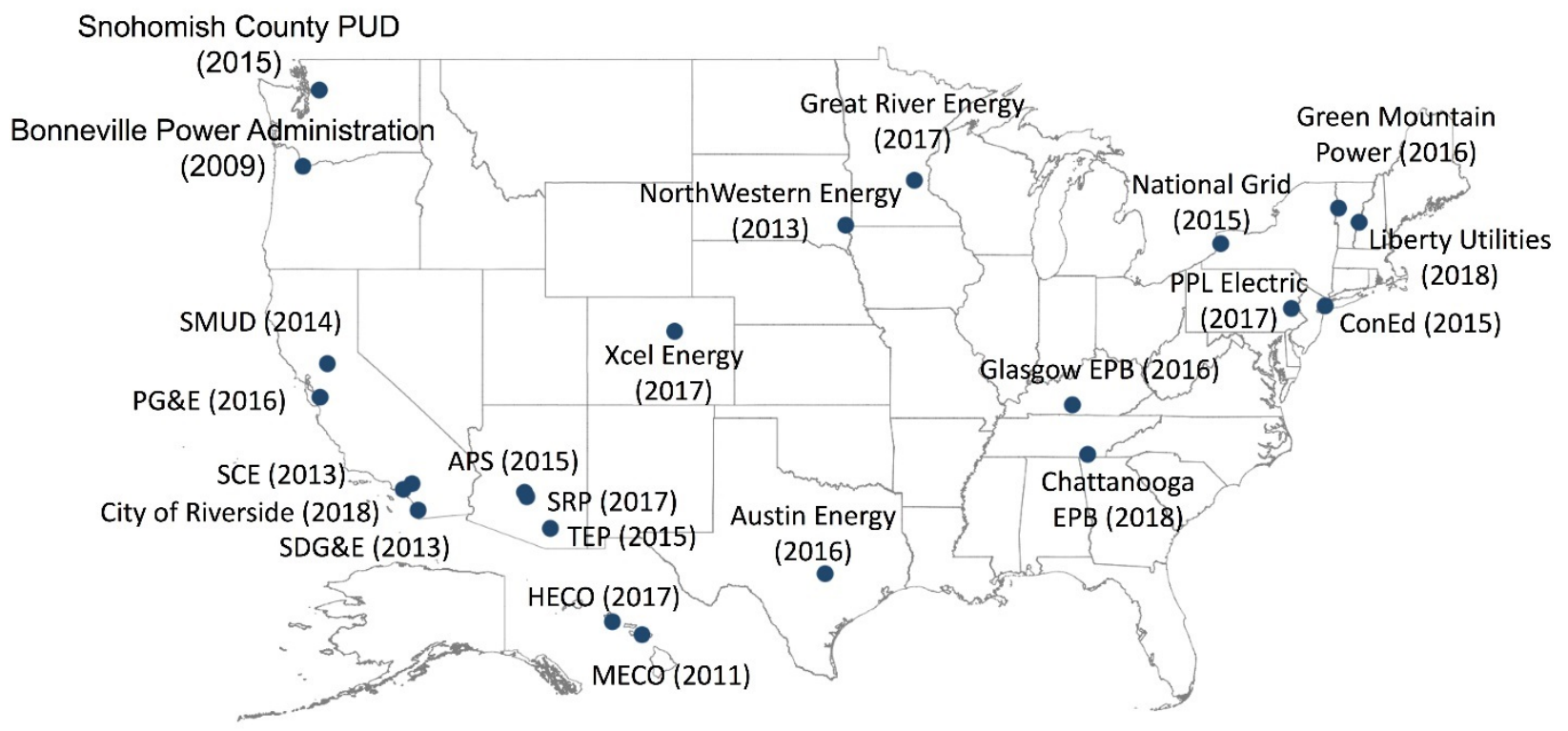

Figure 2. DER aggregation initiatives in the United States, by utility (year launched in parentheses)

Sixteen of the DER aggregation initiatives incorporate PV, while only three do not (Table 1). The remaining four projects are in varying stages of development and may incorporate PV along with other technologies when finalized. Though 13 projects couple PV with batteries, only three use a broader set of DERs including batteries, EVs, home appliances, and PV.

Table 1. DER Aggregation Programs by Select DERs

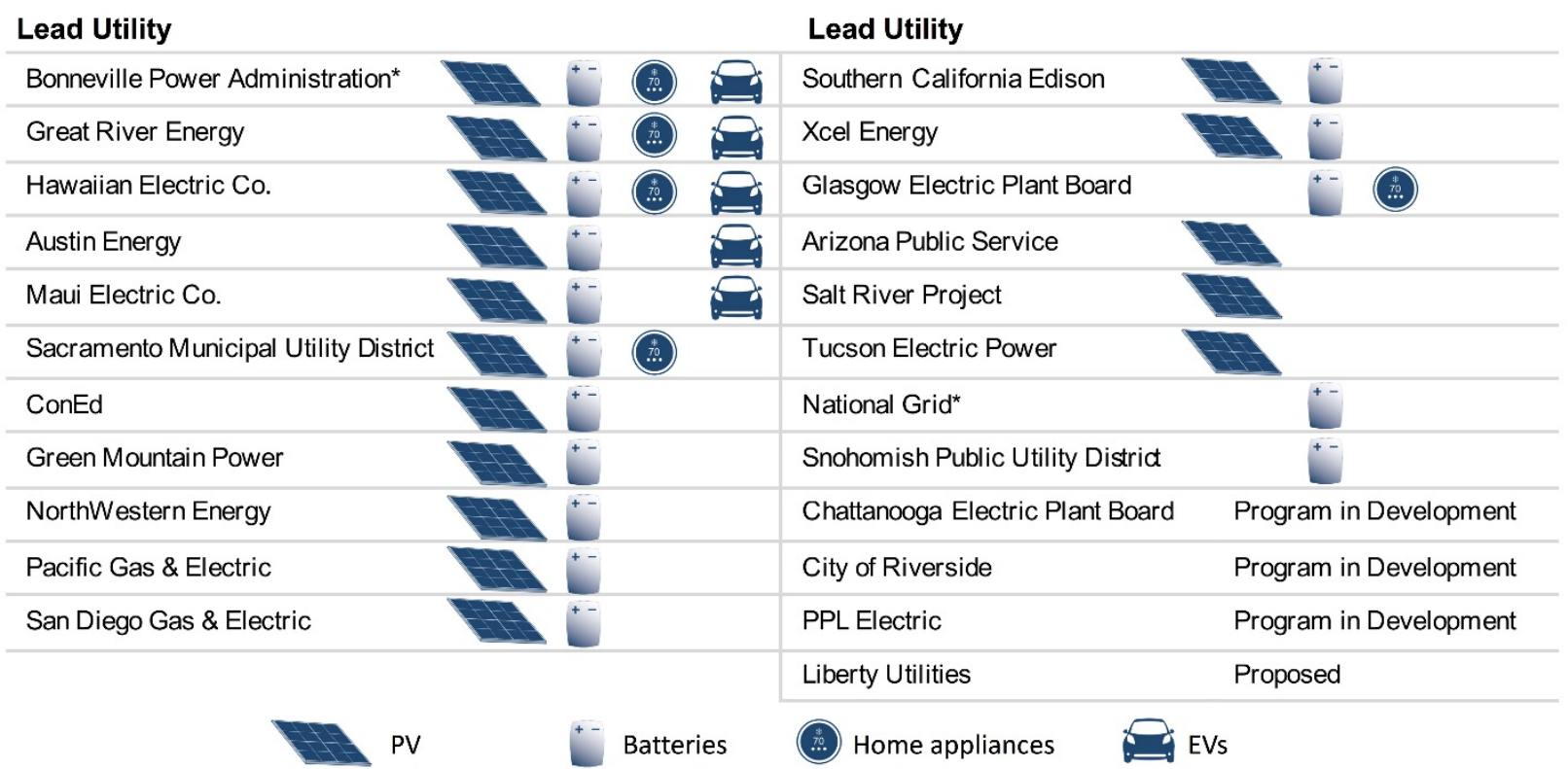

${ }^{*}$ Program includes other DERs, such as diesel generators, outside the scope of this report. 


\section{DER Aggregation Program Design and Performance}

To compare the performance of grid services provision across utility-led DER aggregation programs, in this section we provide five project case studies:

- Green Mountain Power - McKnight Lane Redevelopment Project

- $\mathrm{MECO}$ - JumpSmart Maui Project

- Pacific Gas \& Electric (PG\&E) - San Jose EPIC Distributed Energy Resource Demonstration Projects

- Southern California Edison (SCE) - Preferred Resources Pilot

- Sacramento Municipal Utility District (SMUD) - 2500 R Midtown Project

We selected the five cases because they incorporate PV along with other DER technologies, and we could obtain performance data. Each project also offers variation in launch year, geography, utility type, deployed DERs, and total capacity (Table 2). This variation provides a stronger basis to assess the potential performance and implementation challenges that may be associated with DER aggregation programs across geographic and regulatory contexts. Though findings from these projects can inform broader program design, utilities will have to consider a range of implementation factors when developing long-term programs, including compensation, which are not assessed here.

Table 2. Summary Comparison of Utility Projects

\begin{tabular}{|c|c|c|c|c|c|}
\hline & $\begin{array}{c}\text { Green } \\
\text { Mountain } \\
\text { Power }\end{array}$ & MECO & PG\&E & SCE & SMUD \\
\hline Launch Year & 2016 & 2011 & 2016 & 2013 & 2014 \\
\hline $\begin{array}{l}\text { Published } \\
\text { Performance } \\
\text { Data }\end{array}$ & Yes & Yes & Yes & Partial & Yes \\
\hline $\begin{array}{l}\text { Geographic } \\
\text { Diversity }\end{array}$ & Vermont & Hawaii & California & California & California \\
\hline Utility Type & $\begin{array}{l}\text { Investor- } \\
\text { owned utility }\end{array}$ & $\begin{array}{l}\text { Investor- } \\
\text { owned } \\
\text { utility }\end{array}$ & $\begin{array}{l}\text { Investor- } \\
\text { owned } \\
\text { utility }\end{array}$ & $\begin{array}{l}\text { Investor-owned } \\
\text { utility }\end{array}$ & $\begin{array}{l}\text { Municipal } \\
\text { utility }\end{array}$ \\
\hline $\begin{array}{l}\text { Technologies } \\
\text { Included }\end{array}$ & $\begin{array}{l}\text { Batteries } \\
\text { and PV }\end{array}$ & $\begin{array}{c}\text { Batteries, } \\
\text { EVs, and } \\
\text { PV }\end{array}$ & $\begin{array}{l}\text { Batteries } \\
\text { and PV }\end{array}$ & Batteries and PV & $\begin{array}{l}\text { Batteries, } \\
\text { home } \\
\text { appliances, } \\
\text { and PV }\end{array}$ \\
\hline $\begin{array}{l}\text { Project PV } \\
\text { Capacity (MW) }\end{array}$ & 0.04 & $0.05^{*}$ & 0.124 & 51 & 0.08 \\
\hline $\begin{array}{l}\text { Project Battery } \\
\text { Capacity (MW) }\end{array}$ & 0.03 & 0.70 & 4.4 & 67 & $0.20^{\star \star}$ \\
\hline
\end{tabular}


** SMUD does not disclose the kW power rating of the batteries included in the project. This estimate assumes each battery is rated at $5 \mathrm{~kW} / 11.7 \mathrm{kWh}$.

We conducted additional archival research and follow-up interviews to develop the five case studies. We used the archival data - including project reports and related materials - to describe project characteristics and results. We interviewed 27 subject-matter experts across the cases, including engineers, program managers, software developers, and other key partners. ${ }^{6}$ The semistructured interviews focused on identifying key challenges, solutions, and lessons learned within each case. In addition, we asked interviewees what lessons learned are most relevant across jurisdictions. The case study results are presented chronologically below by launch date: MECO, SCE, SMUD, Green Mountain Power, and PG\&E.

\subsection{MECO - JumpSmart Maui Project}

MECO serves load on the Island of Maui, where residents are increasingly adopting distributed PV and EVs (Bucanega et al. 2016, Irie 2017). To address potential grid challenges with integrating these resources, MECO partnered with its sister utility HECO, Hitachi, and other partners to complete the JumpSmart Maui Project (2011-2016). The project had three general goals:

- Manage power quality and provide customers more access and control over energy consumption.

- Develop solutions for a high penetration of renewables on the grid.

- Maximize the use of renewable energy through DER aggregation and management.

The project had a broad scope and encompassed a wide variety of technologies (Bucanega et al. 2016). For this report, we focus on the technologies related directly to DER aggregation:

- One standalone 153-kWh lithium-ion battery

- One standalone 576-kWh lead-acid battery

- 80 bidirectional chargers $^{7}$ for EVs with 6-kW batteries at homes that already had rooftop PV

- 10 smart inverters at rooftop PV households

The DERs were managed and controlled directly by MECO's software and equipment partner, Hitachi. Hitachi developed its own DERMS — known as the Smart City Platform - to communicate directly with the batteries and EVs at participants' homes (Bucanega et al. 2016). The 10 PV systems with smart inverters were automatically controlled by the inverter to respond to voltage signals from a smart device on the local transformer. Hitachi would then dispatch the batteries and EVs in response to signals and load forecasts supplied by MECO.

\footnotetext{
${ }^{6}$ Ten of these interviewees were related to the PG\&E case, while the remaining 17 interviews were spread across the other four cases.

${ }^{7}$ A bidirectional charger allows an EV to consume or export electricity to the grid.
} 


\subsubsection{Key Results}

The JumpSmart Maui Project successfully demonstrated a wide variety of functions, including many related to DER aggregation. Hitachi used each DER to provide different grid services (Irie 2017). ${ }^{8}$ The batteries demonstrated frequency response. The EVs with bidirectional chargers consumed excess electricity, including during times of higher grid-connected wind generation from $10 \mathrm{PM}-4 \mathrm{AM}$ and PV generation from $12-4 \mathrm{PM}$. The EVs then discharged electricity to the grid during the peak demand period (6-9 PM), when renewable generation was lower. Finally, the $10 \mathrm{PV}$ arrays with smart inverters provided voltage support in response to voltage signals from a local transformer.

The 80 EVs showed the most potential to maximize renewable energy consumption. Figure 3 shows EV charging before the project began (left graph) and an average day in September 2016, when Hitachi was managing EV charging (right graph). The EVs charged during the off-peak time, when wind generation was highest. The EVs then either reduced charging or were discharged at peak (6-9 PM) to reduce the utility's peak demand. At maximum, the EVs provided about $3 \mathrm{~kW}$ of peak load reduction through discharged electricity. Hitachi saw from the pilot that $14 \%-31 \%$ of $\mathrm{EV}$ batteries at homes may be available for discharge at peak times, while $2.1 \%-3.9 \%$ may be available for charging during peak solar generation (10 - 4 PM) (Irie 2017).

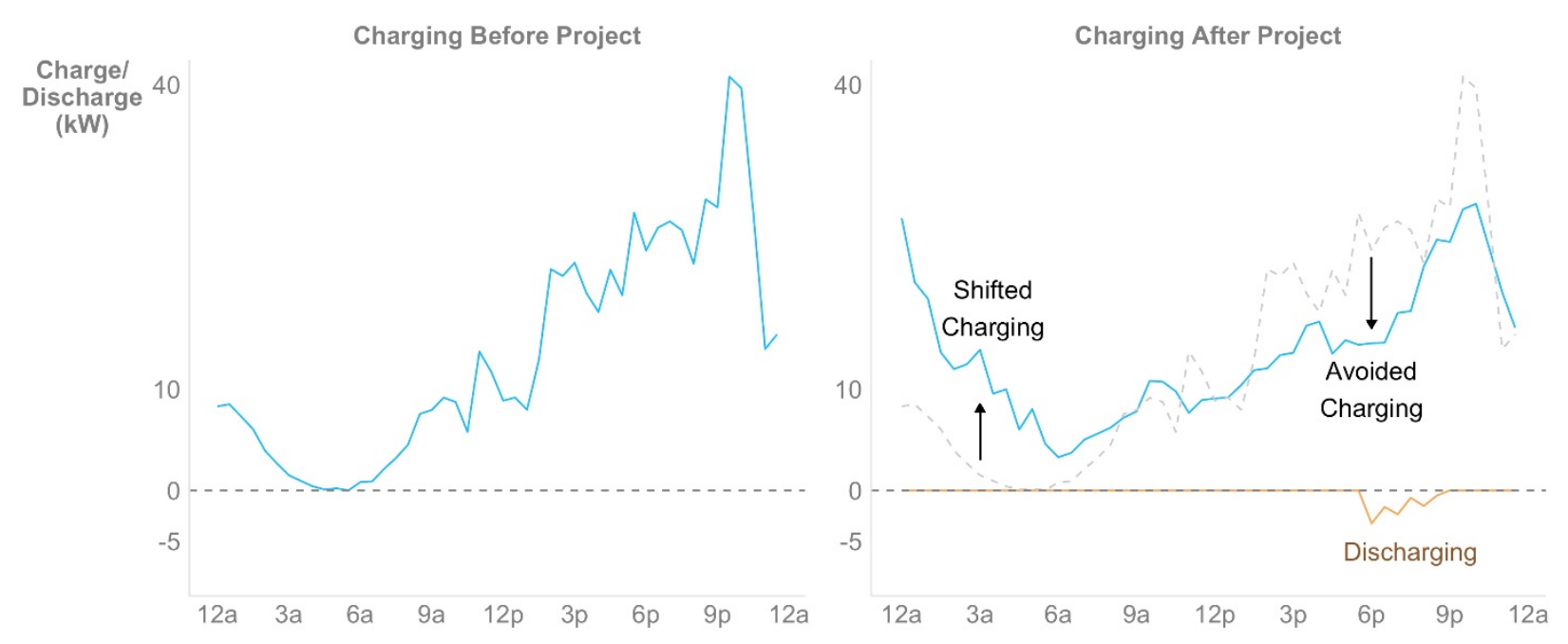

Figure 3. JumpSmart Maui Project EV load-shifting performance, September 2016 (recreated from Irie 2017)

\subsubsection{Lessons Learned}

For the DER aggregation components of the project, lessons learned centered around customer acquisition, PV smart inverter deployment, and use of EVs for maximizing renewable energy consumption. Hitachi and the JumpSmart Maui partners initially struggled to recruit participants, but recruitment improved after the utility developed a more robust and coordinated outreach campaign with local partners including the Maui Economic Development Board (Bucanega et al. 2016). Still, the project did not recruit enough participants to deploy PV paired with residential batteries as originally planned; interviewees explained that the reduction in net-metering

\footnotetext{
${ }^{8}$ More detailed results are included in a New Energy and Industrial Technology Development Organization commissioned report that is available by request in Japanese.
} 
compensation due to using batteries, which would change the economics of residential PV, contributed to this recruiting challenge.

Implementing smart inverter technology to provide voltage support from PV was also difficult. At the time the project's smart inverter was developed, UL, a safety and quality test laboratory for commercial products, had not finalized the UL 1741 Standard for Inverters, Converters, Controllers and Interconnection System Equipment for Use with Distributed Energy Resources. ${ }^{9}$ This standard provides guidelines for construction standards to mitigate electrical, fire, and other hazards. Interviewees suggested that, without the standard, the equipment developer had limited guidance on how to design a smart inverter for MECO's electrical grid, which required additional time and resources.

The use of EVs to support high renewable energy penetration provided three key lessons related to communication, exporting stored electricity, and performance. First, the program relied upon one type of EV and charger, which facilitated communication with and control of the EVs. Because multiple EV and charger types are available, interviewees suggested integrating and coordinating these different models may be more challenging in future programs.

Second, the EVs were prohibited from discharging their full battery capacity $(6 \mathrm{~kW})$ during peak demand periods to ensure participants complied with the net-metering requirement that all exported generation consist of 100\% renewable electricity. Because EVs may charge with nonrenewable grid electricity, EV discharge during peak periods was limited to less than $1 \mathrm{~kW}$ for no more than 30 minutes from 6 - 9 PM (Irie 2017). Subsequent programs designed to capture the full value of EVs may require new tariff structures.

Finally, the ability of EVs to provide DER services depended more on charging schedules and EV locations compared with other DERs, because EVs are mobile and may not be connected to the grid when called upon. Even when EVs are connected to the grid, they may already be near full charge and thus limited in their ability to consume excess PV generation, especially during high PV generation times. Including more workplace charging in the program might result in higher EV performance, because EVs charging at work likely would have a lower state of charge compared with those charging at home during the day (Irie 2017).

\subsection{SCE - Preferred Resources Pilot}

In 2013, SCE was faced with planned retirements of coastal power plants in its service territory (SCE 2016). These planned retirements, along with estimates of higher urban load growth in pockets of the utility's Western Los Angeles Basin (e.g., Orange County), generated an expected need for energy resources to maintain reliable service. SCE, on its own initiative, pursued "preferred resources" (a mix of energy efficiency, load shifting, energy storage, demand response, and PV) to help offset this need. SCE launched the Preferred Resources Pilot (PRP) to understand how a diverse portfolio of preferred resources can meet local capacity needs, thereby deferring or eliminating the need for new natural-gas power plants.

The PRP was designed in three phases. Phase 1 was completed in 2014 (SCE 2018). During this phase, SCE established the pilot framework, conducted customer outreach, and began acquiring

\footnotetext{
${ }^{9}$ For more information on the standard, see https://standardscatalog.ul.com/standards/en/standard 17412.
} 
DERs. During Phase 2, which began in 2015 and is scheduled to end in 2018, SCE will procure a total of $256 \mathrm{MW}$ of DERs in the study region and of the deployed resources, measure their performance to reliably serve local area needs. Phase 3 will begin at the close of the demonstration phase in 2018 and extend through 2022. At this stage, SCE will develop sustainable processes to maintain the preferred resources to provide local capacity services. This stage will also include analyses related to the project's impact on interconnection, distribution planning, and grid operations.

\subsubsection{Key Results}

SCE is currently in the demonstration phase of this project and has deployed $74 \mathrm{MW}$ of preferred resources in the focus region. The utility has acquired an additional $182 \mathrm{MW}$ of capacity, of which $56 \mathrm{MW}$ is expected to be deployed by October 2018 (SCE 2018). ${ }^{10}$ At full buildout, energy efficiency and permanent load shifting combined will be the largest preferred resource in the pilot, followed by energy storage, demand response, and PV (Figure 4). ${ }^{11}$

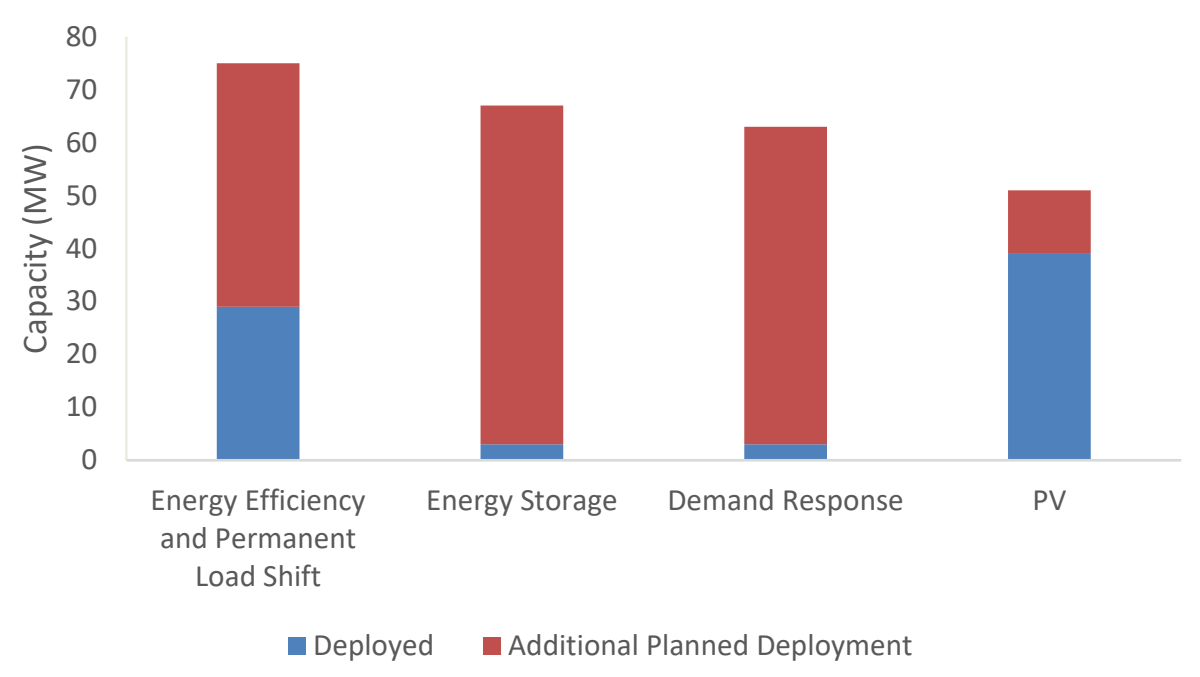

Figure 4. PRP capacity by preferred resource type

Figure 5 shows the contribution of the deployed preferred resources at peak for 2 days in August 2017. On August 3 (left graph), the resources provided approximately $50 \mathrm{MW}$ of capacity during the 5-hour peak period, serving all peak demand for 2 of those hours (above a $971 \mathrm{MW}$ demand baseline). On August 31 (right graph), the resources provided similar capacity at peak, but they could not meet demand for any peak hour owing to the higher load and the portfolio of resources not being fully deployed. For both days, PV served the most demand, followed by existing combined heat and power systems also located in the PRP region. As more contracted capacity comes online, including battery storage, SCE will continue to evaluate the performance of DERs and how they contribute to meeting peak demand.

\footnotetext{
${ }^{10} \mathrm{SCE}$ received regulatory approval for cost recovery of $125 \mathrm{MW}$ of capacity related to the PRP on July 12, 2018 (CPUC 2018).

${ }^{11}$ According to interviewees, planned energy efficiency capacity is largely associated with commercial and industrial customer savings in heating, ventilation, and cooling, followed by lighting and other energy conservation measures. The demand response capacity is largely associated with additional behind-the-meter energy storage.
} 
Peak Event: 8/3/2017

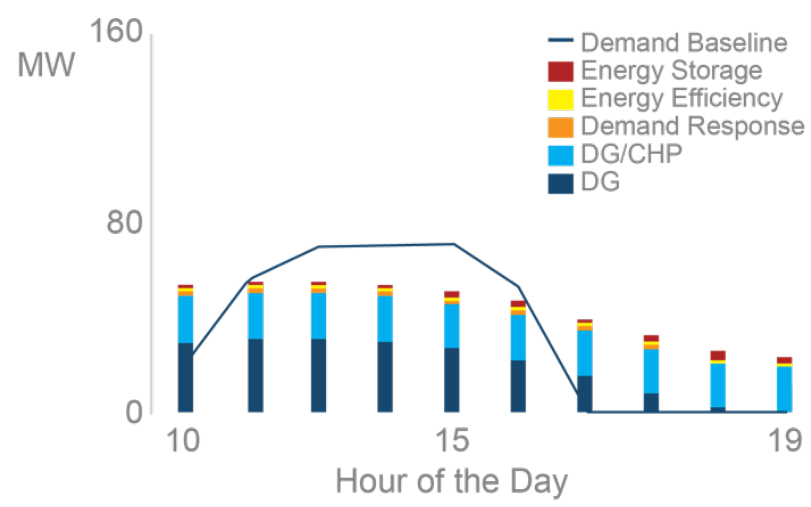

Peak Event: 8/31/2017

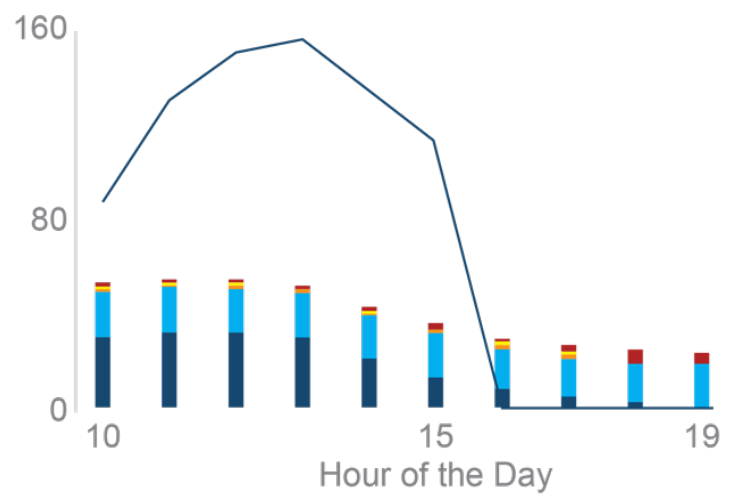

Figure 5. Assessed DER performance and customer demand for 2 days in PRP region; the demand shown is peak demand above baseline demand of $971 \mathrm{MW}$ (recreated from SCE 2018)

Note: DG/CHP refers to existing distributed generation combined heat and power capacity deployed in 2015 in the PRP region. This resource was not procured for this demonstration, but it can help serve local needs and is consider part of the resource mix.

\subsubsection{Lessons Learned}

Lessons learned to date relate to estimating PV's capacity contribution, procuring DERs, and developing a DERMS that is compatible with DER aggregator technology. Much of the existing PV deployed on the system is behind-the-meter, and SCE's limited visibility with regard to the generation of those systems on the distribution grid makes it challenging to assess PV's contribution to local capacity needs. To address this challenge, SCE studied PV's contribution during peak times, concluding that $95 \%$ of metered systems are likely to produce at least $40 \%$ of nameplate capacity at peak (SCE 2017). Interviewees noted that this estimate will continue to be revised as the utility assesses DER performance and customer load through 2022.

Though SCE was successful in demonstrating the ability to acquire a portfolio of DERs to serve local needs, during the competitive portion of the DER acquisition process, SCE received fewer PV bids and more energy storage bids than expected. Interviewees posited that the lack of PV bids, in this highly urban area, might have been due to challenges associated with enlisting hundreds of residential customers, which makes economies of scale challenging for commercial developers. Developers may have also had challenges contracting with commercial customers who may rent their facilities and do not have the rights to install PV. At the same time, some battery storage project costs have declined (ESA and GTM Research 2018), which may have increased the number of energy storage bids. As a result, interviewees suggested it's important not to prejudge, or prescribe, a portfolio mix but instead focus on acquiring DERs to meet the specific resources attributes needed (e.g., $10 \mathrm{MW}$ available for 2-4 hours on certain summer days). The goal for SCE is now to demonstrate that the resources can be deployed to meet grid needs.

Finally, developing a DERMS and communicating with DERs have also presented challenges. Interviewees said that pilot development of a DERMS is time and resource intensive. SCE is currently using a test DERMS but expects to adopt a full DERMS before the project's conclusion. Interviewees suggested that the publication of IEEE 2030.5-2018 Standard for Smart Energy Profile Application Protocol, designed to support communication between the utility and 
DERs, will help address communication challenges by providing a common communication framework for control technologies. ${ }^{12}$

\subsection{SMUD - 2500 R Midtown Project}

SMUD launched and completed the $2500 \mathrm{R}$ Midtown project in 2014 to test the functionality of DER control technology in providing grid benefits. SMUD's key partners for the $2500 \mathrm{R}$ Midtown project included Sunverge Energy Inc., ThinkEco, and Pacific Housing Inc. (ADM Associates Inc. 2014). ${ }^{13}$ The project included 34 newly constructed single-family homes outfitted with a 2.25-kW PV array, an 11.7-kWh lithium-ion battery, a smart thermostat, and a "modlet." ${ }^{14}$ SMUD then used subsets of these homes to test the following use cases:

- Load shifting: demonstrate the ability of the DERs to offer bill savings throughout the program period by shaving or shifting load at peak times.

- Fleet operation in aggregate: demonstrate the ability to coordinate multiple homes with DERs to operate as a group.

- Uninterruptible power source: demonstrate PV and battery islanding functionality to provide backup power to critical load during a grid outage and successfully reconnect to the grid.

- Power quality: demonstrate that the PV and battery operate in acceptable voltage, frequency, and harmonic distortion ranges.

- PV firming: demonstrate that the PV and battery mitigate rapid output changes from PV panels.

- Regulation: demonstrate that the PV and battery can respond to regulation pulse signal and adjust load delivery.

\subsubsection{Key Results}

The project successfully demonstrated all six use cases prior to completion in December 2014. From a DER aggregation perspective, the first two use cases - load shifting and fleet operationare the most applicable and occurred in tandem. Ten of the 34 homeowners volunteered to participate in a time-of-use rate schedule and have their DERs controlled directly by SMUD. SMUD operated these 10 homes as a fleet to provide load-shifting services during "conservation days"-12 of the highest peak demand days on SMUD's system. On each conservation day, SMUD required the battery to store midday PV generation and discharge that electricity during the peak period (4-6 PM). The smart thermostat cooling set point was lowered prior to the peak period to precool the home, and it was raised during the peak period to reduce air conditioning load. Finally, the power to appliances plugged into modlets was turned off during the peak period.

\footnotetext{
${ }^{12}$ For more information on the standards, see https://standards.ieee.org/findstds/standard/2030.5-2018.html.

${ }^{13}$ For more information on pilot studies completed after those articulated in ADM Associates Inc. (2014), see Energy and Environmental Economics Inc. (2016).

${ }^{14}$ A modlet refers to a 120 -volt wall outlet device that can be remotely activated to control electricity flow to the appliances plugged into the outlet (ADM Associates Inc. 2014).
} 
On an average conservation day, the 10 homes shifted a maximum of $43.8 \mathrm{~kW}$ during the peak period (Figure 6). The average home provided $2.66 \mathrm{~kW}$ of demand savings during a conservation day. The PV and battery provided most of this load shift at $2.47 \mathrm{~kW}$, followed by the smart thermostat $(0.18 \mathrm{~kW})$ and the modlet $(0.004 \mathrm{~kW})$ (ADM Associates Inc. 2014).

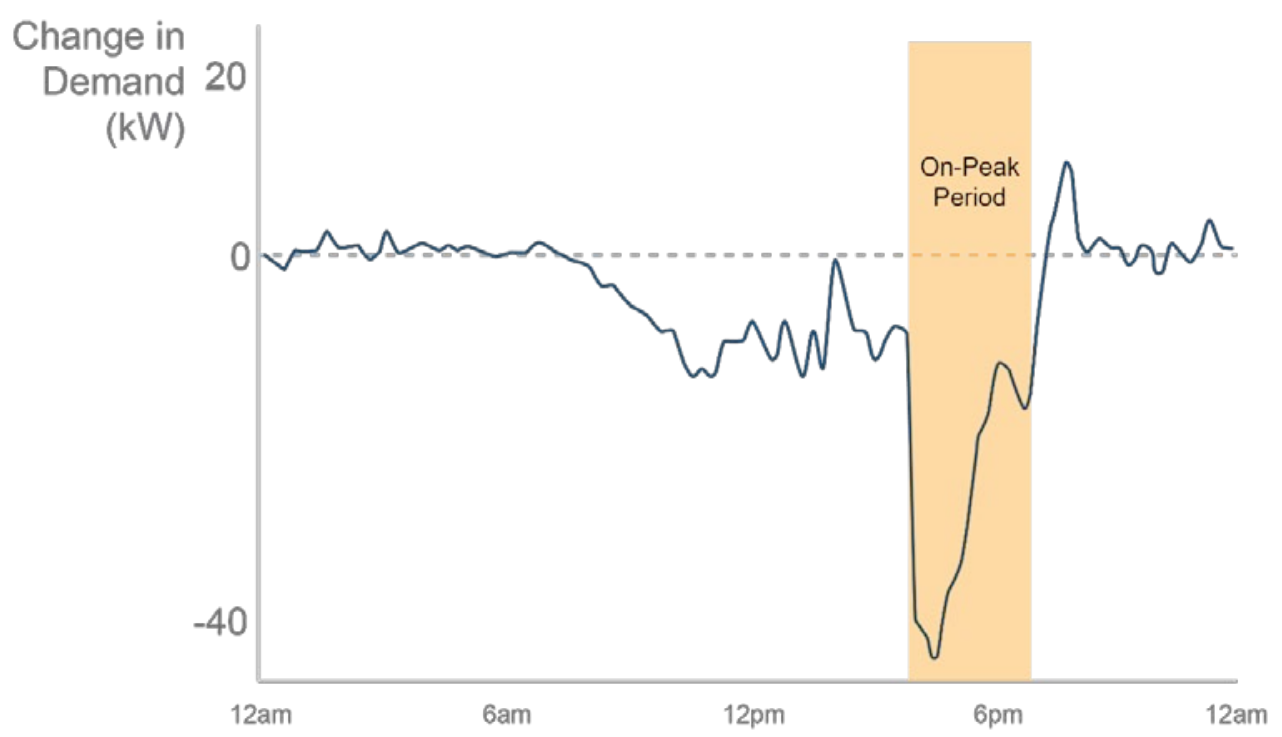

Figure 6. Total household fleet load-shifting profile for an average conservation day (recreated from ADM Associates Inc. 2014)

\subsubsection{Lessons Learned}

Lessons learned relate to integrating DERs into a DERMS platform, siting and performance of certain DERs, communication with those DERs, and considerations for next-generation DER aggregation programs. In the context of DERMS development and DER integration, one interviewee noted that communicating with specific third-party platforms was not the key challenge; rather, it was difficult to identify cost-effective pathways to manage integration and data exchange across the utility and third-party platforms. The interviewee suggested that DERMS technology improvements have made this easier, but open communication platforms will be hindered by third-party interests to protect proprietary information.

Local authorities having jurisdiction (AHJs) had limited understanding of customer-sited battery storage, which required SMUD and project partners to work with these authorities to ensure battery systems could be sited at the new homes. One interviewee suggested that, although these discussions did not delay the overall project timeline, they may have caused delays if construction required a faster timeline.

SMUD questioned the value of smart thermostats and modlets as implemented in the project. Smart thermostat performance was inconsistent, and the cooling data were not fully available, prompting SMUD to call for additional analysis into the value of these resources. The modlets typically provided very low demand response capacity, because the plugged loads were small and consumed less than $2 \mathrm{~W}$ of power $80 \%$ of the time (ADM Associates Inc. 2014). 
The project also generated considerations for future programs. An interviewee noted that participating homeowners were sent manually generated emails calling for a conservation day, and a larger program would require an automated system for both customer notice and dispatch. In addition, SMUD suggested that DERs might provide regulation services, but more analysis was needed to verify that response and increase confidence in DER capacity (ADM Associates Inc. 2014). Finally, SMUD suggested that the six demonstrated use cases may serve different or cross purposes. As a result, the utility might benefit from developing a use-case prioritization process (ADM Associates Inc. 2014). The design of this prioritization process might impact the value to the end-use customer, which could influence customer interest in next-generation programs.

\subsection{Green Mountain Power - McKnight Lane Redevelopment Project}

In 2016, the McKnight Lane Redevelopment project replaced 14 manufactured housing units with seven net-zero energy modular duplex-homes in Waltham, Vermont. Green Mountain Power was a key partner in the project along with Addison County Community Trust, Sonnen, and the Vermont Community Development Program, among many others (Donalds, Galbraith, and Olinsky-Paul 2018). The seven modular duplexes were equipped with a 6-kW PV array, a 4$\mathrm{kW} / 6-\mathrm{kWh}$ lithium-ion battery, and various energy efficiency measures such as heat pump water heaters and cold climate heat pump compressors. ${ }^{15}$ Green Mountain Power then communicated with the battery systems via a DERMS platform developed by Virtual Peaker (Ferreira 2016).

The project's goals spanned affordable housing, air quality, and DER aggregation. As to DER aggregation, the project had three key objectives:

- Peak demand reduction: demonstrate PV and battery system capacity to reduce annual and monthly peak demand from ISO New England.

- Energy arbitrage: deploy battery systems in the ISO New England day-ahead and realtime markets to buy and sell energy.

- Transmission and distribution upgrade deferral: demonstrate PV and battery benefit in alleviating congestion and thereby offsetting the need for infrastructure upgrades.

\subsubsection{Key Results}

The McKnight Lane Redevelopment project has met two of its three DER aggregation goals, including peak load reduction and transmission and distribution upgrade deferral. ${ }^{16}$ Because the battery systems represent a comparatively small load, Green Mountain Power has not disclosed a quantitative infrastructure-deferral benefit, though it does plan to assess this value (Ferreira 2016; Donalds, Galbraith, and Olinsky-Paul 2018). In any case, peak demand reduction is the utility's highest-priority value proposition, so those results are shown here.

Green Mountain Power planned to use the battery systems for annual and monthly peak demand reduction. Because ISO New England experienced an unusually early annual peak demand event

\footnotetext{
${ }^{15}$ One unit was equipped with a 4-kW/8-kWh lithium-ion battery (Donalds, Galbraith, and Olinsky-Paul 2018).

${ }^{16}$ The utility is still implementing the energy arbitrage component of the project (Donalds, Galbraith, and OlinskyPaul 2018).
} 
on June 13, 2017, Green Mountain Power was unable to deploy the battery fleet to serve this peak (Ferreira 2016; Donalds, Galbraith, and Olinsky-Paul 2018). However, it successfully discharged the batteries to reduce monthly peak demand. Specifically, Green Mountain Power dispatches the battery fleet for 2 hours to align with the typical 2-hour duration of peak demand events for ISO New England (Figure 7), resulting in an aggregate demand reduction of $44.65 \mathrm{~kW}$ (Ferreira 2016). ${ }^{17}$ This load reduction represents a \$350-\$400 monthly cost savings on behalf of all ratepayers (Donalds, Galbraith, and Olinsky-Paul 2018).

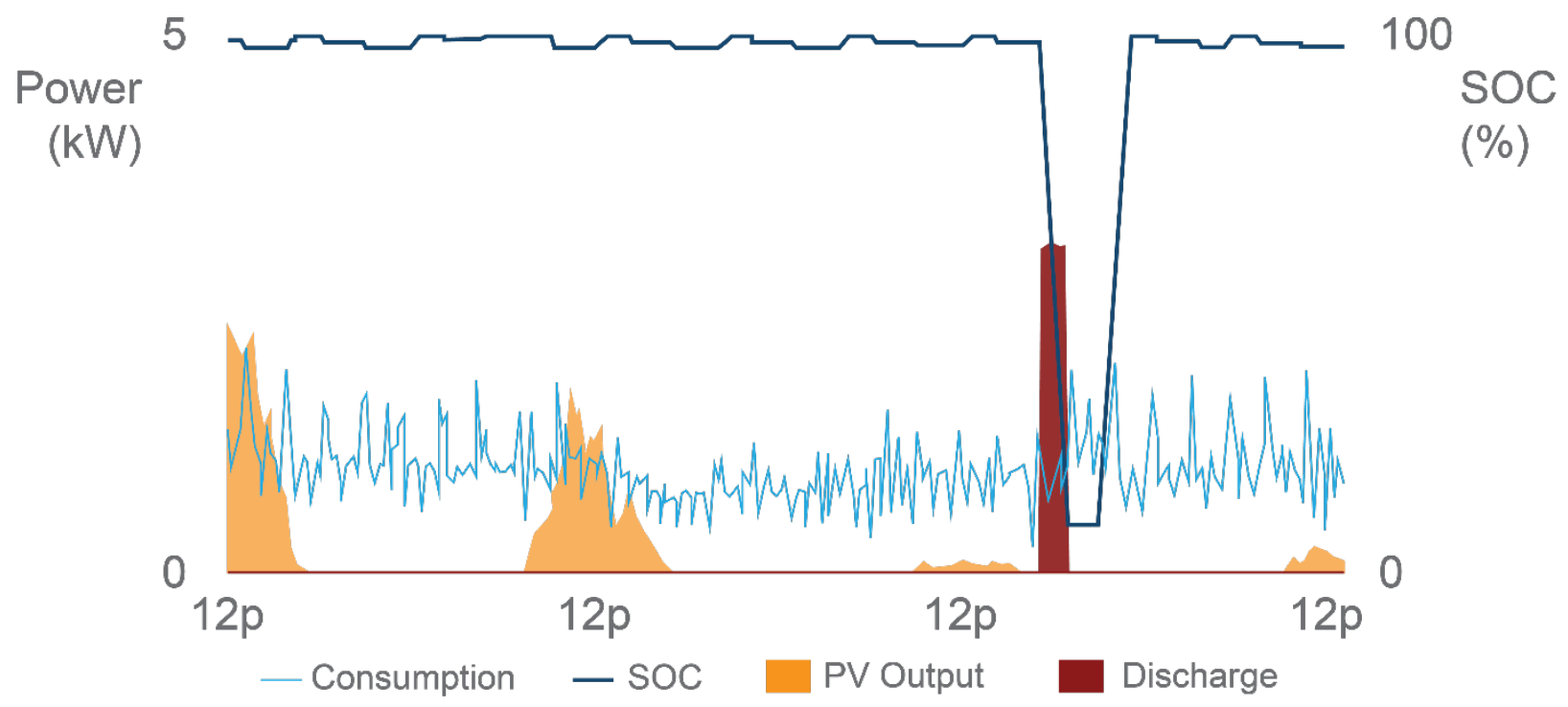

Figure 7. Battery and PV operation from one duplex around the monthly ISO New England peak period, February 2018 (recreated from Donalds, Galbraith, and Olinsky-Paul 2018)

Note: SOC refers to battery state of charge

\subsubsection{Lessons Learned}

The McKnight Lane Redevelopment project provides lessons learned about communicating with DERs, deploying DERs to meet peak demand, and developing a DERMS to manage a variety of DERs. ${ }^{18}$ The utility experienced challenges with establishing communication between the batteries and the DERMS, stemming in part from battery or inverter hardware issues (Donalds, Galbraith, and Olinsky-Paul 2018). In some cases, these challenges required replacing the equipment. Once the batteries were deployed and communication systems tested, the utility still faced communication issues when calling on the batteries to respond. This required frequent visits back to the site to reestablish communication (Donalds, Galbraith, and Olinsky-Paul 2018). Interviewees suggested that some issues related to communication with the modems that controlled the batteries. These modems also had to be reset manually, adding delay and cost. Technology innovation and minimizing links in the chain of communication were both sited by interviewees as methods to improve communication reliability in future programs.

\footnotetext{
${ }^{17}$ While peak demand shaving is a priority for Green Mountain Power, the utility ensures that the battery fleet always maintains a minimum $10 \%$ state of charge to allow for backup power provision in the event of a grid outage.

${ }^{18}$ For a broader discussion of lessons learned in relation to the goals of this project, see Donalds, Galbraith, and Olinsky-Paul (2018).
} 
Using batteries to offset peak demand also has entailed challenges. Green Mountain Power's manual programming of the batteries increased time and resource requirements. Automating the system should reduce time and resource requirements and may help time battery discharge to meet difficult-to-predict peak demands without the need for improved peak forecasting methods. Green Mountain Power plans to automate activities related to peak demand reduction and energy arbitrage going forward (Donalds, Galbraith, and Olinsky-Paul 2018). Employing this manual process, the utility ultimately failed to meet its annual peak load reduction objective, given the unpredictable nature of the peak. As a result, without improved forecasting methods and tools, a utility may be unable to use DERs to reliably provide peak reduction. Nevertheless, when the utility did successfully predict peak, the DERs performed as expected.

Finally, the project has demonstrated the complexities of developing a DERMS system. An interviewee commented that DERMS developers have different processes and timelines for incorporating resources. Thus, it was important to select a vendor that provided functionality and a timeline aligned with utility goals.

\subsection{Pacific Gas \& Electric - San Jose EPIC Distributed Energy Resource Demonstration Projects}

In 2016, PG\&E launched the San Jose Distributed Energy Resource Demonstration Projects composed of three collocated research projects supported by the California Energy Commission, project 2.02, 2.03A, and 2.19 (PG\&E 2017). This case study focuses on Project 2.02 Distributed Energy Resource Management System. For this project, PG\&E had three partners: General Electric (GE), Tesla, and Green Charge Network (GCN) (PG\&E 2016). Through this project, PG\&E aimed to field-validate core DERMS capabilities in a high-penetration DER environment. GE developed the proof of concept DERMS platform, while Tesla and GCN served as the aggregators for $124 \mathrm{~kW}$ of residential PV, $66 \mathrm{~kW}$ of residential lithium-ion battery storage in 27 homes, and $360 \mathrm{~kW}$ of commercial lithium-ion battery storage at 3 commercial locations (Ardani et al. 2018). PG\&E also incorporated a 4-MW PG\&E-owned sodium sulfur battery in the demonstration project.

The project tested six DERMS-related use cases:

- Provide situational awareness of actual and forecasted DER-related grid conditions in real time.

- Manage equipment capacity constraints by coordinating DERs to mitigate overload issues.

- Mitigate voltage issues by controlling the real and reactive power output of DERs.

- Dispatch DERs based on economic factors such as costs and external price signals.

- Improve operational flexibility by developing forecasts and optimizations during abnormal switching configurations through DERs.

- Demonstrate coordination of behind- and in-front-of-the-meter DERs to provide distribution grid services and bid into wholesale markets. 


\subsubsection{Key Results}

Though full results are not yet public, PG\&E's early results indicate the potential viability of all six use cases at demonstration scale (Ardani et al. 2018). The DERMS has successfully integrated load and PV generation forecasts to anticipate current and future demand requirements. In line with this situational awareness, the DERMS has predicted capacity constraints and voltage violations on the system and dispatched DERs to mitigate these issues. A comprehensive summary of PG\&E's project, including the quantitative results associated with each use case will be published in 2018 (Ardani et al. 2018). Here, we offer one illustrative example of the DERMS deploying DERs to mitigate a forecasted overload situation. Figure 8 demonstrates that the DERMS estimated an overload on the system at about 8 PM, after PV generation declines and demand peaks. The DERMS compensated for this estimated overload by charging batteries during peak generation and discharging those batteries to address the overload situation.

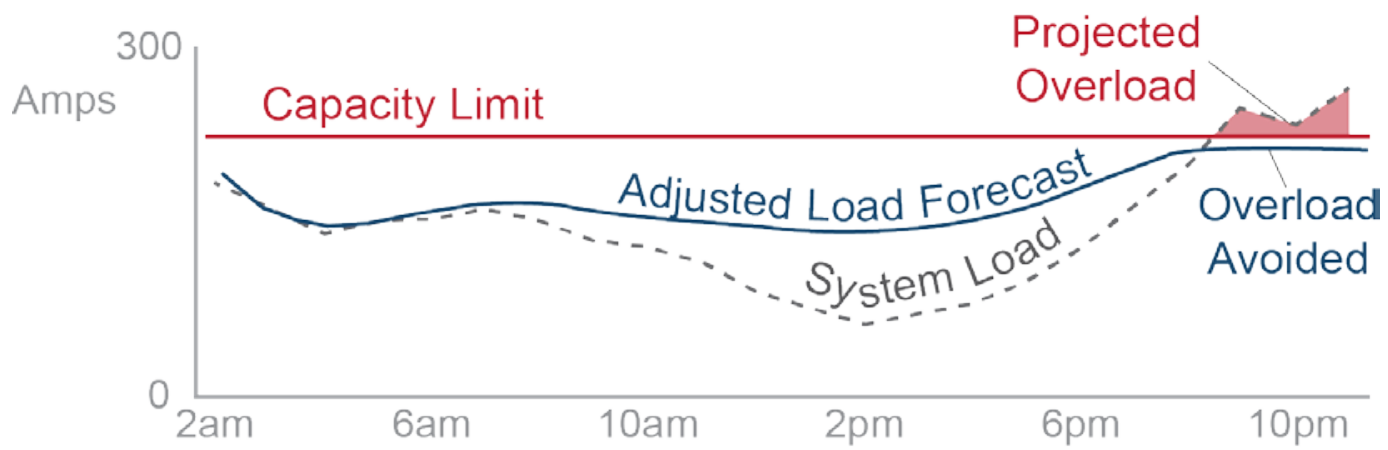

Figure 8. Example of DERMS-forecasted overload mitigation (recreated from Portilla 2017)

\subsubsection{Lessons Learned}

PG\&E's efforts offered a variety of insights and the focus here is on some of the key lessons relating to software development and integration, customer acquisition, DER deployment, and DER communication. PG\&E was interested in working with multiple third-party aggregators to better understand differences in aggregator performance and the complexity associated with integrating these aggregators into one DERMS software platform (Ardani et al. 2018). Working with multiple aggregators provided benefits relating to collaboration and problem solving as well as diversifying DERs. However, the utility faced challenges with coordinating these aggregators and incorporating different sets of communication standards within the DERMS platform. These challenges can add time and cost to the program. The utility addressed some of this challenge by implementing the use cases in sequence from less to more complex. This allowed the utility to build on lessons learned at each stage and address points of failure before adding complexity. In order to scale these types of programs in the future, further standardization of protocols and operational practices will be required.

PG\&E also faced unexpected customer-acquisition challenges, in part because the project needed to recruit non-PV customers because the original hardware configuration made retrofits difficult (Ardani et al. 2018). Now that homes with PV systems can be more easily retrofitted with batteries due to hardware innovation, this challenge may be mitigated in other locations. For those customers that did sign up, PG\&E faced unanticipated permitting and interconnection challenges (PG\&E 2018a). PG\&E noted that the City of San Jose had limited experience 
permitting solar plus battery systems resulting in a lack of standardization and streamlined permitting processes. As a result, each system was addressed individually and often required multiple inspections, which added to construction timelines (PG\&E 2018a).

Once the DERs were deployed, PG\&E faced challenges with communicating with remote DERs. Residential internet connections served as the communication link between PG\&E and the DERs and these connections were not always consistent (PG\&E 2018b). In addition, PG\&E found some cases of incorrect data or gaps in reported data particularly when batteries were tripped offline. Some of these challenges were resolved in the longer than expected acceptance testing stage, but others persisted throughout the demonstration such as challenges relating to inconsistent internet connections.

Finally, PG\&E was pleased with the DERMS demonstrated capability to maximize DER performance for distribution and wholesale markets. First, the DERMS allowed PG\&E to aggregate multiple assets with shared characteristics into groups termed "nodes" (Ardani et al. 2018). PG\&E could communicate with and deploy these nodes as one aggregated resource within the DERMS to provide certain grid services. This allowed the utility to more effectively address challenges in certain geographies and deploy resources that are most appropriate for certain grid services. In addition, PG\&E found the DERMS could coordinate DERs participating in both distribution and wholesale markets. Building out this functionality, would be important to scale and coordinate DER activity across these different markets to maximize grid value (Ardani et al. 2018). 


\section{Conclusions}

Despite the unique context of each DER aggregation project, the pilots shared common challenges relating to DERMS development and implementation, customer acquisition, DER deployment, communicating with DERs, and DER performance. This section summarizes those challenges, the key lessons learned, and considerations for resolving these issues in the next generation of programs.

Table 3 summarizes the challenges faced by each of the utilities in relation to five categories. In some cases, the utilities faced similar issues within a given category. For example, three of the five utilities had challenges with developing DERMS software to control a disparate set of DER technologies and participants. In other cases, the utilities' experiences and challenges varied substantially. For example, Green Mountain Power, PG\&E, and SCE found that DERs performed as expected, whereas the other two utilities found that the performance of different technologies varied. Though these challenges can be interrelated, the remainder of this section discusses each challenge separately with perspectives from interviewees on how utilities might resolve each challenge.

Table 3. Summary of Key DER Program Challenges by Utility and Category

\begin{tabular}{|c|c|c|c|c|c|}
\hline Key Challenge & MECO & SMUD & $\begin{array}{l}\text { Green } \\
\text { Mountain } \\
\text { Power }\end{array}$ & SCE & PG\&E \\
\hline $\begin{array}{l}\text { DERMS } \\
\text { Development } \\
\text { and } \\
\text { Implementation }\end{array}$ & & $\begin{array}{c}\text { Software } \\
\text { compatibility }\end{array}$ & & $\begin{array}{c}\text { Software } \\
\text { compatibility }\end{array}$ & $\begin{array}{l}\text { Software } \\
\text { compatibility }\end{array}$ \\
\hline $\begin{array}{l}\text { Customer } \\
\text { Acquisition }\end{array}$ & $\begin{array}{l}\text { Securing } \\
\text { participants }\end{array}$ & & & & $\begin{array}{l}\text { Securing } \\
\text { participants }\end{array}$ \\
\hline $\begin{array}{l}\text { DER } \\
\text { Deployment }\end{array}$ & $\begin{array}{l}\text { Battery } \\
\text { uptake and } \\
\text { inverter } \\
\text { design }\end{array}$ & $\begin{array}{l}\text { Storage } \\
\text { permitting }\end{array}$ & & & $\begin{array}{c}\text { Storage } \\
\text { permitting and } \\
\text { interconnection }\end{array}$ \\
\hline $\begin{array}{l}\text { Communicating } \\
\text { with DERs }\end{array}$ & & $\begin{array}{l}\text { DER data } \\
\text { communication } \\
\text { gaps }\end{array}$ & $\begin{array}{l}\text { Establishing } \\
\text { initial } \\
\text { communication }\end{array}$ & $\begin{array}{l}\text { DER data } \\
\text { communication } \\
\text { gaps }\end{array}$ & $\begin{array}{c}\text { DER data } \\
\text { communication } \\
\text { gaps }\end{array}$ \\
\hline $\begin{array}{l}\text { DER } \\
\text { Performance }\end{array}$ & $\begin{array}{c}\text { EV } \\
\text { performance } \\
\text { varied }\end{array}$ & $\begin{array}{c}\text { Home } \\
\text { appliance } \\
\text { performance } \\
\text { varied }\end{array}$ & & & \\
\hline
\end{tabular}

To scale DER aggregation programs, utilities likely need to develop a DERMS and find cost-effective pathways to integrate DERs with different communication protocols. In all five cases, the utility, or its partners, developed a temporary or permanent DERMS to aggregate and deploy DERs. A DERMS likely will be essential to scale aggregation programs given the need to develop situational awareness of DER performance, the ability to securely and reliably interact with those DERs, and optimally dispatch them to provide grid services autonomously. The cases demonstrate that developing a DERMS can be challenging, but Green Mountain 
Power and PG\&E's approach to phase in DERMS functionality may help mitigate some of these challenges. This approach could serve as a model for other utilities. Interviewees also offered some perspective on how utilities might address integration challenges, particularly when developing a program that includes DER aggregators. Ensuring the DERMS can interact with aggregator software adds complexity, costs, and cybersecurity concerns (Rodriguez Labastida and Asmus 2018). Interviewees suggested that aggregator software platforms are just emerging, so technology innovation may streamline the time and resources needed to develop, test, and integrate these systems. Several interviewees suggested that the use of open communication standards may also help developers and aggregators integrate disparate DER technologies regardless of their make and model. The IEEE 2030.5 Standard for Smart Energy Profile Application Protocol is one effort to standardize communication protocols between the utility, aggregators, and individual DERs. Widespread adoption of similar open or standardized communication protocols may reduce the time and resources needed to develop and implement a DER aggregation program.

To secure customer participation, utilities should consider how DER aggregation will impact or align with existing DER incentive structures so that potential customers see a net benefit of participation. The MECO and PG\&E cases both demonstrate the potential challenges with acquiring customers. Location, availability, and concentration of DERs are essential considerations for assessing the role these resources can play in providing grid value. Utilities need to balance these considerations and related value, with existing DER incentive structures to gauge potential customer interest in DER aggregation. MECO's project partner, Hitachi, and PG\&E faced customer-acquisition challenges. In the case of Hitachi, these challenges stemmed in part from the poor economic value proposition of PV and batteries compared with net-metered PV on MECO's grid. As a result, utilities may need to seek alternative rate or other compensation structures to foster customer interest in DER aggregation programs. If customers do not see a reasonable return, they will be unlikely to participate. Interviewees also suggested that utilities should adequately explain program design and requirements before signing up customers to ensure that the customers make informed choices. Other utilities might wish to evaluate these factors prior to program adoption and then adjust their customer-acquisition process or program design accordingly.

To reduce deployment-related delays, utilities could work proactively with AHJs to resolve permitting issues particularly for batteries. Hitachi did not deploy enough residential batteries to test this deployment challenge in the MECO pilot, while SMUD and PG\&E faced AHJ permitting challenges. Battery permitting uncertainty can cause delays and additional costs as was the case for PG\&E and SMUD. Though not evident in our cases, these challenges can also result in project termination. For example, Consolidated Edison's (Con Ed's) Clean Virtual Power Plant in New York was terminated after the utility could not secure approval from the New York City Department of Buildings and the New York Fire Department to install residential batteries. Con Ed remained committed to this concept and conducted a battery storage safety analysis to provide permitting authorities with more information on safe battery siting in New York City (Con Ed 2017). In addition, the New York State Energy Research and Development Authority (NYSERDA) has offered \$8.1 million in technical assistance to support the development of energy storage permitting guidelines, model codes, and standards to streamline future permitting costs (NYSERDA 2016, NYSERDA 2018). These initiatives are similar to ongoing efforts to streamline PV permitting process and may help other utilities that are 
considering incorporating batteries in their DER aggregation programs. ${ }^{19}$ Even so, utilities and other DER aggregation partners may wish to discuss battery storage deployment and permitting requirements with AHJs early in the process to address and resolve permitting issues.

To secure anticipated grid services from deployed DERs, utilities likely need to pursue methods to increase communication reliability between the utility, aggregators, and/or individual DERs. Four utilities faced communication challenges with deployed DERs. For example, Green Mountain Power encountered issues with faulty equipment, limited communication, and the need to reset equipment manually (Donalds, Galbraith, and OlinskyPaul 2018). In addition, interviewees from this case suggested that failures in the communication chain between the individual DER, the aggregator, and the utility also impacted DER performance. Ongoing efforts to streamline communication chains could help reduce the probability of failure. PG\&E, SMUD and SCE also had issues with the data they received in response from DERs, even with consistent lines of communication as demonstrated by SMUD and SCE. Utilities may want to consider these types of challenges when determining which DERs to include in their programs and when developing data-communication requirements for DERs to receive compensation for grid services.

To more accurately predict DER performance, utilities should evaluate how technology mix, operation protocols, and consumer behavior may impact individual DER performance. Hitachi found that EV capacity varied depending on the time of day, which was due in part to the mobile nature of EVs and the MECO project's focus on residential charging (Irie 2017). In comparison, SMUD found that smart thermostats in its program offered inconsistent demand response (ADM Associates Inc. 2014). The utility could not confirm what caused this variation, given the lack of data, and said more research was necessary to understand how reliable these resources could be (ADM Associates Inc. 2014). Thus, utilities may want to consider how DER technology performance may vary in their programs and adjust program design as necessary.

\footnotetext{
${ }^{19}$ For more information on ongoing efforts to streamline permitting and construction processes for PV see Day and
} Aznar (2018). 


\section{References}

ADM Associates Inc. 2014. Sacramento Municipal Utility District 2500 R Street Integrated Energy Management Use Case Report. Sacramento: Sacramento Municipal Utility District. https://www.smud.org/-/media/Documents/Corporate/About-Us/Energy-Research-andDevelopment/research-2500-R-Street-entegrated-energyevaluation.ashx?la=en\&hash=B2943042C0C1BB3A9037FC69259DAF8BEE2E6B25.

Ardani, K., E. O'Shaughnessy, P. Schwabe, and R. Margolis. 2018. Coordinating Distributed Energy Resources to Increase Grid Flexibility: A Case Study of Pacific Gas and Electric. Golden, CO: National Renewable Energy Laboratory.

Aznar, A. and M. Day. 2018. "Communities Are Becoming "SolSmart" (With Some Help From Their States)." Solar STAT Blog. Golden, CO: National Renewable Energy Laboratory. https://www.nrel.gov/technical-assistance/blog/posts/communities-are-becoming-solsmart-withsome-help-from-their-states.html.

Braff, W., J.M. Mueller, and J.E. Trancik. 2016. "Value of Storage Technologies for Wind and Solar Energy." Nature Climate Change 6: 964-969. https://www.nature.com/articles/NCLIMATE3045.

Bucanega, D. Jr., K. George, G. Horst, and S. Kasai. 2016. JumpSmartMaui Demonstration Project Phase 1 Assessment: EPRI Smart Grid Demonstration Initiative. Palo Alto, CA: Electric Power Research Institute. https://www.epri.com/\#/pages/product/000000003002007129/?lang=en.

Coddington, M., M. Miller, and J. Katz. 2016. Grid-Integrated Distributed Solar: Addressing Challenges for Operations and Planning. NREL/FS-6A20-63042. Golden, CO: National Renewable Energy Laboratory. https://www.nrel.gov/docs/fy16osti/63042.pdf.

Colthorpe, A. 2017. "Tesla Launches First Aggregated 'Virtual Power Plant' in US.” Energy Storage News, May 16, 2017. https://www.energy-storage.news/news/tesla-launches-firstaggregated-virtual-power-plant-offering-in-us.

Con Ed (Consolidated Edison). 2017. REV Demonstration Project: Clean Virtual Power Plant $20171 Q$ Quarterly Progress Report - Notice of Temporary Suspension of the Clean Virtual Power Plant Project. New York State Department of Public Service. http://documents.dps.ny.gov/public/Common/ViewDoc.aspx?DocRefId=\%7B6512D405-FA944BA6-B89D-732E53206358\%7D.

CPUC (California Public Utilities Commission). 2018. Decision Approving the Results of Southern California Edison Company's Second Preferred Resources Pilot Procurement. San Francisco: CPUC.

http://docs.cpuc.ca.gov/PublishedDocs/Published/G000/M217/K835/217835818.PDF.

Denholm, P., K. Clark, and M. O'Connell. 2016. On the Path to SunShot: Emerging Issues and Challenges in Integrating High Levels of Solar into the Electrical Generation and Transmission 
System. NREL/TP-6A20-65800. Golden, CO: National Renewable Energy Laboratory. http://www.nrel.gov/docs/fy16osti/65800.pdf.

Donalds, S., S. Galbraith, and T. Olinsky-Paul. 2018. McKnight Lane Redevelopment Project. Montpelier, VT: Clean Energy Group. https://www.cleanegroup.org/wpcontent/uploads/McKnight-Lane-Case-Study-June-2018.pdf.

EIA (U.S. Energy Information Administration). 2018. "Frequently Asked Questions: What is U.S. electricity generation by energy source?" Accessed 2018.

https://www.eia.gov/tools/faqs/faq.php?id=427\&t=3.

Energy and Environmental Economics Inc. 2016. PV Integrated Storage: Demonstrating Mutually Beneficial Utility-Customer Business Partnerships. Go Solar California. http://www.calsolarresearch.ca.gov/images/stories/documents/Sol4_funded_proj_docs/E34_Cutt er/4_CSI-RDD_Sol4_E3 PV-Integrated-Storage_FinalRpt_2016-08.pdf.

ESA (Energy Storage Association) and GTM Research. 2018. U.S. Energy Storage Monitor: 2017 Year In Review and Q1 2018 Full Report. Boston: GTM Research. https://www.greentechmedia.com/research/report/us-energy-storage-monitor-2017-year-inreview\#gs.PSvszxg.

Feblowitz, Jill. 2017. "Virtual Power Plants: Ready to Serve a Grid Near You." GreenTech Media, July 18, 2017. https://www.greentechmedia.com/articles/read/virtual-power-plants-readyto-serve-a-grid-near-you\#gs.nNXgTSw.

FERC (Federal Energy Regulatory Commission). 2017. Assessment of Demand Response and Advanced Metering. Washington, DC: FERC. https://www.ferc.gov/legal/staff-reports/2017/DRAM-Report2017.pdf.

Ferreira, C. 2016. "McKnight Lane: A Rural, Low-Income, Zero-Energy Solar+Storage Housing Project." Clean Energy Group Webinar, December 14, 2016. https://www.cleanegroup.org/wpcontent/uploads/rpp-webinar-slides-12.14.16.pdf.

GTM Research and SEIA (Solar Energy Industries Association). 2018. U.S. Solar Market Insight Full Report 2017 Year in Review. Washington, DC: SEIA. https://www.seia.org/researchresources/solar-market-insight-report-2017-year-review.

Gundlach, J., and R. Webb. 2018. "Distributed Energy Resource Participation in Wholesale Markets: Lessons from the California ISO.” Energy Law Journal 39(1): 47-77. http://columbiaclimatelaw.com/files/2018/05/Gundlach-and-Webb-2018-05-DER-in-WholesaleMarkets.pdf.

Irie, H. 2017. Japan - U.S. Collaborative Smart Grid Demonstration Project in Maui Island of Hawaii State: A Case Study. NEDO New Energy and Industrial Technology Development Organization. http://www.nedo.go.jp/content/100864936.pdf.

Lazar, J. 2016. Teaching the "Duck" to Fly, Second Edition. Montpelier, VT: The Regulatory Assistance Project. http://www.raponline.org/document/download/id/7956. 
Mulherkar, A. 2017. North American DER Management Systems 2017-2020: Market Evolution, Competitive Analysis, and Forecast. Boston: GTM Research.

https://www.greentechmedia.com/research/report/der-management-systems-2017\#gs.sRv1VIg.

NYSERDA (New York State Energy Research and Development Authority). 2018. "Technical Assistance." Accessed 2018. https://www.nyserda.ny.gov/All-Programs/Programs/EnergyStorage/Funding-and-Assistance/Technical-Assistance.

NYSERDA (New York State Energy Research and Development Authority). 2016. Reducing Distributed Energy Storage Soft Costs. Albany: NYSERDA. https://www.nyserda.ny.gov//media/Files/FO/Closed-Opportunities/2016/3407summary.pdf.

Patel, S. 2012. "The Rise of the Virtual Power Plant." Power Magazine, July 1, 2012. http://www.powermag.com/the-rise-of-the-virtual-power-plant/.

PG\&E (Pacific Gas \& Electric). 2018a. EPIC 2.19 - Enable Distributed Demand-side Strategies \& Technologies. https://www.pge.com/pge_global/common/pdfs/about-pge/environment/whatwe-are-doing/electric-program-investment-charge/PGE-EPIC-Project-2.19.pdf.

PG\&E (Pacific Gas \& Electric). 2018b. EPIC 2.03A: Test Capabilities of Customer-Sited Behind-the-meter Smart Inverters. https://www.pge.com/pge_global/common/pdfs/aboutpge/environment/what-we-are-doing/electric-program-investment-charge/PGE-EPIC-Project2.03a.pdf?WT.mc id=Vanity epicinterimreport-SmartInverters.

PG\&E (Pacific Gas \& Electric). 2017. 2016 Annual Electric Program Investment Charge Report of Pacific Gas and Electric Company (U 39 E). https://www.pge.com/pge_global/common/pdfs/about-pge/environment/what-we-aredoing/electric-program-investment-charge/2016-EPIC-Annual-Report.pdf.

PG\&E (Pacific Gas \& Electric). 2016. "PG\&E Launches Distributed Energy Resource Projects Testing Technology to Unlock Benefits of the Grid.” Press release, July 12, 2016. https://www.pge.com/en/about/newsroom/newsdetails/index.page?title=20160712_pge launches _distributed_energy_resource projects testing technology to unlock benefits_of the _grid_.

Portilla, A. 2017. "PG\&E DERMS Demonstration Experience." Presented at the Distributech Conference and Exhibition, San Diego, CA, January 31 - February 2, 2017.

Reuters. 2018. "South Australia Promises World's Largest Virtual Power Plant.” Reuters, February 3, 2018. https://www.reuters.com/article/us-australia-power-tesla/south-australiapromises-worlds-largest-virtual-power-plant-idUSKBN1FO02G.

Rodriguez Labastida, R., and P. Asmus. 2018. Distributed Renewables Aggregation Strategies in VPPs. Navigant Research. https://www.navigantresearch.com/research/distributed-renewablesaggregation-strategies-in-vpps.

SCE (Southern California Edison). 2018. SCE Preferred Resources Pilot Annual Update. Rosemead, CA: SCE. https://www.sce.com/wps/wcm/connect/e134c4a9-aff0-4ddf-a8a0cf9d5a0e3304/2017_PRPAnnualReport.pdf?MOD=AJPERES. 
SCE (Southern California Edison). 2017. Calculating a Dependable Solar Generation Curve for SCE's Preferred Resources Pilot October 2017. Rosemead, CA: SCE. https://www.sce.com/wps/wcm/connect/37f93bcf-f376-47a1-ab9ff14297cfc192/PRP_SolarDependabilityWhitePaper.pdf?MOD=AJPERES.

SCE (Southern California Edison). 2016. SCE's Preferred Resources Pilot. Rosemead, CA:

SCE. https://www.sce.com/wps/wcm/connect/1ac76183-53c2-4762-8db24d52345dfa74/SCE_PRPOverview.pdf?MOD=AJPERES.

Seal, B., A. Renjit, and B. Deaver. 2018. Understanding DERMS. Palo Alto, CA: Electric Power Research Institute. https://www.epri.com/\#/pages/product/000000003002013049/?lang=en.

Shallenberger, K. 2017. "DER Aggregation: Sector Experts Identify Emerging Trends in a Nascent Market." Utility Dive, July 24, 2017. https://www.utilitydive.com/news/der-aggregationsector-experts-identify-emerging-trends-in-a-nascent-marke/447670/.

Siemens. 2016. "Hawaiian Electric Selects Siemens as Technology Partner for DOE SunShot Solar Initiative.” Press release, February 9, 2016. http://news.usa.siemens.biz/pressrelease/hawaiian-electric-selects-siemens-technology-partner-doe-sunshot-solar-initiative.

Tweed, K. 2010. "The Top Five Players in Demand Response." GreenTech Media, July 19, 2010. https://www.greentechmedia.com/articles/read/top-5-demand-response\#gs.EVacCbA. 


\section{Appendix}

Table 4. Identified Utility-led DER Aggregation Programs by Year

\begin{tabular}{|c|c|c|c|c|}
\hline Project Name & $\begin{array}{l}\text { Launch } \\
\text { Year }\end{array}$ & State & Lead Utility & $\begin{array}{l}\text { Technology } \\
\text { Summary }\end{array}$ \\
\hline $\begin{array}{l}\text { Pacific Northwest Smart Grid } \\
\text { Demonstration Project }\end{array}$ & 2009 & Oregon & $\begin{array}{c}\text { Bonneville } \\
\text { Power } \\
\text { Administration }\end{array}$ & $\begin{array}{c}\text { Batteries, EVs, } \\
\text { home appliances, } \\
\text { PV }\end{array}$ \\
\hline JumpSmart Maui & 2011 & Hawaii & $\begin{array}{l}\text { Maui Electric } \\
\text { Company }\end{array}$ & $\begin{array}{c}\text { Batteries, EVs, } \\
\text { home appliances, } \\
\text { PV }\end{array}$ \\
\hline $\begin{array}{l}\text { Distributed Energy Resource } \\
\text { Management System }\end{array}$ & 2013 & California & $\begin{array}{l}\text { San Diego Gas } \\
\text { \& Electric }\end{array}$ & Batteries, PV \\
\hline NA & 2013 & South Dakota & $\begin{array}{l}\text { NorthWestern } \\
\text { Energy }\end{array}$ & Batteries, PV \\
\hline Preferred Resources Pilot & 2013 & California & $\begin{array}{l}\text { Southern } \\
\text { California } \\
\text { Edison }\end{array}$ & Batteries, PV \\
\hline 2500 R Midtown & 2014 & California & $\begin{array}{l}\text { Sacramento } \\
\text { Municipal } \\
\text { Utility District }\end{array}$ & $\begin{array}{l}\text { Batteries, home } \\
\text { appliances, PV }\end{array}$ \\
\hline Energy Storage Program & 2015 & Washington & $\begin{array}{l}\text { Snohomish } \\
\text { County Public } \\
\text { Utility District }\end{array}$ & Batteries \\
\hline $\begin{array}{l}\text { Distributed System Platform } \\
\text { Demonstration Project }\end{array}$ & 2015 & New York & National Grid & $\begin{array}{l}\text { Batteries, fossil } \\
\text { generators }\end{array}$ \\
\hline $\begin{array}{l}\text { Clean Virtual Power Plant } \\
\text { Demonstration Project }\end{array}$ & 2015 & New York & $\begin{array}{l}\text { Consolidated } \\
\text { Edison }\end{array}$ & Batteries, PV \\
\hline Solar Partner Program & 2015 & Arizona & $\begin{array}{l}\text { Arizona Public } \\
\text { Service }\end{array}$ & PV \\
\hline Residential Solar Program & 2015 & Arizona & $\begin{array}{l}\text { Tucson } \\
\text { Electric Power }\end{array}$ & PV \\
\hline $\begin{array}{l}\text { Glasgow Smart Energy } \\
\text { Technologies }\end{array}$ & 2016 & Kentucky & $\begin{array}{c}\text { Glasgow } \\
\text { Electric Power } \\
\text { Board }\end{array}$ & $\begin{array}{l}\text { Batteries, home } \\
\text { appliances }\end{array}$ \\
\hline Austin SHINES & 2016 & Texas & Austin Energy & Batteries, PV \\
\hline McKnight Lane Project & 2016 & Vermont & $\begin{array}{l}\text { Green } \\
\text { Mountain } \\
\text { Power }\end{array}$ & Batteries, PV \\
\hline $\begin{array}{l}\text { San Jose Distributed Energy } \\
\text { Resource Demonstration Project }\end{array}$ & 2016 & California & $\begin{array}{l}\text { Pacific Gas \& } \\
\quad \text { Electric }\end{array}$ & $\begin{array}{l}\text { Batteries, home } \\
\text { appliances, PV }\end{array}$ \\
\hline Advanced Inverter Pilot & 2017 & Arizona & $\begin{array}{l}\text { Salt River } \\
\text { Project }\end{array}$ & PV \\
\hline Community Storage Project & 2017 & Colorado & Xcel Energy & Batteries, PV \\
\hline
\end{tabular}




\begin{tabular}{|c|c|c|c|c|}
\hline HECO DR Portfolio & 2017 & Hawaii & $\begin{array}{l}\text { Hawaiian } \\
\text { Electric } \\
\text { Company }\end{array}$ & $\begin{array}{c}\text { Batteries, EVs, } \\
\text { home appliances, } \\
\text { PV }\end{array}$ \\
\hline $\begin{array}{l}\text { Keystone Solar Energy Future } \\
\text { Project }\end{array}$ & 2017 & Pennsylvania & $\begin{array}{l}\text { PPL Electric } \\
\text { Utilities }\end{array}$ & TBD \\
\hline NA & 2017 & Minnesota & $\begin{array}{l}\text { Great River } \\
\text { Energy }\end{array}$ & $\begin{array}{c}\text { Batteries, EVs, } \\
\text { home appliances, } \\
\text { PV }\end{array}$ \\
\hline CleanstartDERMS & 2018 & California & $\begin{array}{c}\text { City of } \\
\text { Riverside } \\
\text { Public Utilities }\end{array}$ & TBD \\
\hline $\begin{array}{l}\text { Distributed Energy Resource } \\
\text { Management System }\end{array}$ & 2018 & Tennessee & $\begin{array}{c}\text { Chattanooga } \\
\text { Electric Power } \\
\text { Board }\end{array}$ & TBD \\
\hline Battery Storage Pilot Program & 2018 & $\begin{array}{c}\text { New } \\
\text { Hampshire }\end{array}$ & Liberty Utilities & Proposed, TBD \\
\hline
\end{tabular}

